\title{
Cyclicality in Catastrophic and Operational Risk Measurements ${ }^{*}$
}

September 2004

\author{
Linda Allen \\ Professor of Finance \\ Department of Economics \& Finance \\ Baruch College, Zicklin School of Business \\ City University of New York \\ One Bernard Baruch Way, Box 10-225 \\ New York, New York 10010 \\ Phone: (646) 312-3463 \\ Fax: (646) 312-3451 \\ E-mail: Linda_Allen@baruch.cuny.edu
}

\author{
Turan G. Bali \\ Associate Professor of Finance \\ Department of Economics \& Finance \\ Baruch College, Zicklin School of Business \\ City University of New York \\ One Bernard Baruch Way, Box 10-225 \\ New York, New York 10010 \\ Phone: (646) 312-3506 \\ Fax: (646) 312-3451 \\ E-mail: Turan_Bali@baruch.cuny.edu
}

\footnotetext{
* We thank Yacine Ait-Sahalia and an anonymous referee for their extremely helpful comments and suggestions. We also thank Rashad Abdel-khalik, Ruth Arad, Gayle Delong, Salih Neftci, Anthony Saunders, and Robert Schwartz, as well as participants at seminars at Baruch College, Hofstra University, Indiana University, Hebrew University, the Office of the Comptroller of the Currency, the Federal Reserve Bank of New York, the Fourth Annual Conference on Financial Regulation in Toronto, the $12^{\text {th }}$ Conference on Pacific Basin Finance, Economics and Accounting in Bangkok, for useful comments. We also benefited from discussions with Tim Bell, Archishman Chakraborty, Jay Dahya, Ozgur Demirtas, Charlotte Hansen, Armen Hovakimian, Susan Ji, Ahmet Karagozoglu, John Merrick, George Papaioannou, Jonathan Wang, Liuren Wu, and Rui Yao on certain theoretical and empirical points. Excellent research support was provided by Yi Tang, Ekkachai Saenyasiri and Irena Yegorova. Financial Support from the KPMG and the University of Illinois Business Measurement Research Program is also gratefully acknowledged. All errors remain our responsibility.
} 


\title{
Cyclicality in Catastrophic and Operational Risk Measurements
}

\begin{abstract}
Using equity returns for financial institutions we estimate both catastrophic and operational risk measures over the period 1973-2003. We find evidence of cyclical components in both the catastrophic and operational risk measures obtained from the Generalized Pareto Distribution and the Skewed Generalized Error Distribution. Our new, comprehensive approach to measuring operational risk shows that approximately $18 \%$ of financial institutions' returns represent compensation for operational risk. However, depository institutions are exposed to operational risk levels that average $39 \%$ of the overall equity risk premium. Moreover, operational risk events are more likely to be the cause of large unexpected catastrophic losses, although when they occur, the losses are smaller than those resulting from a combination of market risk, credit risk or other risk events.
\end{abstract}

Keywords: operational risk, catastrophic risk, value at risk, extreme value theory, skewed fat tailed distribution.

JEL Code: G20, C13 


\section{Cyclicality in Catastrophic and Operational Risk Measurements}

A natural point of departure for all elements of business risk measurement is the past. Future trends and current metrics are often extrapolated from an historical data series. However, this process is fundamentally flawed if there are cyclical factors that impact business measures of risk or performance. Historical data on operational risk gathered during an economic expansion may not be relevant for a period of recession. Estimates of default risk and recovery rates incorporate cyclical components that are correlated to systematic risk factors, such as macroeconomic fluctuations and regulatory shifts. All too frequently, however, researchers and practitioners alike ignore these cyclical factors and blithely extend an unadjusted trend line into the future. The metrics obtained using this methodology are fundamentally flawed. By aggregating across different macroeconomic regimes, these historical estimates do not accurately reflect either time period. It is the goal of this paper to demonstrate the importance of developing models to adjust for systematic and cyclical risk factors in business metrics.

Neglect of cyclical components in business and risk measurement is not the result of an oversight. Indeed, currently one of the major impediments to the adoption of the BIS New Capital Accord for international bank regulations is the proposal's neglect of cyclical factors. ${ }^{1}$ Concerns focus on the procyclical nature of credit risk. That is, if there are systemic cyclicalities in bank risk exposures, for example, then aggregate bank capital requirements that are based on risk measurements with significant cyclical components may experience cyclical swings that may have unintended, adverse impacts on the macroeconomy. For example, if credit risk models overstate (understate) default risk in bad (good) times, then internal bank capital requirements will be set too high (low) in bad (good) times, thereby forcing capital-constrained banks to retrench on lending during recessions and expand lending during booms. Since most banks are subject to the same cyclical fluctuations, the overall macroeconomic effect of capital regulations is to exacerbate business cycles, thereby worsening recessions and overheating expanding economies - that is, the risk-adjusted capital requirements proposed by the BIS Basel Committee on Banking Supervision are procyclical. $^{2}$

Academic and business researchers acknowledge the importance of cyclical factors in business measures of risk and performance. Allen and Saunders $(2002,2004)$ survey the state of the literature on adjusting risk measures for macroeconomic factors. Lowe (2002) suggests that a business cycle view would result in recessions following expansions and vice versa in a pattern similar to a sine wave. However, the poor track record of economic forecasting might cast doubts on such a simple specification of cyclical

\footnotetext{
1 For description of the BIS proposals, see BIS (January 2001, March 2001, September 2001, March 2002).

2 Of course, prudential supervision could be used to mitigate these systemic factors, as in the case of "ring-fencing," which is the supervisory process of "protecting a bank from adverse impact of events occurring in the wider corporate group, especially those engaging in unsupervised activities." BIS (March 2002, p. 51).
} 
effects. Lowe (2002) acknowledges the difficulties in incorporating more complex cyclical models. Most risk measurement models, therefore, assume that key parameters are independent of macroeconomic factors.

This paper tests and rejects that hypothesis. We explicitly test whether cyclical risk factors are incorporated into measures of operational risk and catastrophic risk exposures in financial institutions. ${ }^{3}$ We find that cyclical factors are significant components of both catastrophic and operational risk. This is the first paper, to our knowledge, to test the cyclicality of operational risk exposures. To accomplish this, we devise a measure of operational risk that encompasses the low frequency, high severity operational loss events, as well as the high frequency, low severity day-to-day operational risk events.

The quantification of operational risk is, in itself, a contribution of our paper. Our new, comprehensive approach to measuring operational risk shows that approximately $18 \%$ of financial institutions' returns represent compensation for operational risk. This result is similar to the estimates obtained using different empirical methodologies by Kuritzkes (2002) and de Fontnouvelle et al. (2003). However, our results suggest that depository institutions are exposed to operational risk levels that average $39 \%$ of the overall equity risk premium. We find that the proportion of overall risk exposure that can be attributed to operational risk varies over time and is, at times, quite large. Moreover, operational risk events are more likely to be the cause of large unexpected catastrophic losses, although when they occur, the losses are smaller, on average, than those resulting from a combination of market risk, credit risk or other risk events. Our results hold when catastrophic risk and operational risk are estimated using two different methodologies: the extreme value theory implemented using the Generalized Pareto Distribution (GPD) of Pickands (1975), and a skewed fattailed distribution implemented using the Skewed Generalized Error Distribution (SGED) of Bali and Theodossiou (2003). Our results are also robust to alternative distributions, as well as to a simulated database.

As of June 2004, the Basel Committee on Banking Supervision has adopted a narrow definition of operational risk for regulatory purposes that focuses on day-to-day loss events emanating from computer failures and human error, for example, while excluding catastrophic operational risk events resulting from reputational losses and strategic business errors. Although this definitional decision may be warranted on pragmatic grounds (i.e., the absence of reliable industry databases on extreme tail operational loss events), the eventual goal is to develop a more comprehensive measure of operational risk that is more consistent

\footnotetext{
${ }^{3}$ If investors can diversify their portfolio holdings, the question may be posed as to why catastrophic risk is at all relevant. One reason may be that catastrophic risk events are highly visible, even to relatively uninformed traders. Merton (1987) and Shapiro (2002) show that portfolio holdings of informationally constrained investors may be impacted by visibility, such that investors may eschew holdings of stocks of firms with negative visibility (e.g., resulting from catastrophic risk events). In addition, in this paper, we consider financial institutions such as banks that have access to a government-subsidized safety net. In exchange for these government subsidies, regulators require banks to maintain capital positions designed to protect the overall safety and soundness of the banking system. Catastrophic risk events may potentially cause contagion and systemic risk problems that undermine this regulatory
} 
with the designation of regulatory capital as a cushion against unexpected loss. ${ }^{4}$ In this paper, we offer a first step toward this ultimate goal. Our "top-down" model can be used to calibrate "bottom-up" operational risk models for the purposes of both regulatory and economic capital determination. ${ }^{5}$ By relying on equity returns to measure operational risk, we measure the impact of operational loss events on overall firm value. Many of the bottom-up models that measure operational risk from a cost perspective can obtain spurious results. For example, if a firm institutes operational risk managerial controls, costs will generally increase thereby leading the bottom-up model to generate estimates of increased risk, but, if the managerial controls are effective, operational risk should actually decrease. Moreover, bottom-up models often suffer from overdisaggregation in that they break down production processes into individual steps that may obscure the broader picture. Finally, bottom-up models rely on subjective data provided by employees that are under scrutiny and therefore have little incentive to be forthcoming. ${ }^{6}$ Thus, a top-down model, such as presented in this paper, that uses an objective data source (e.g., equity returns) should be a useful complement to the bottom-up operational risk models currently under development.

The paper is organized as follows. Section I describes the database. Sections II and III provide the properties and estimation procedures of the GPD and SGED distributions, respectively. Section IV shows alternative VaR models based on the GPD and SGED density. Section V determines the presence and significance of cyclical factors in catastrophic risk measures. Section VI defines a new, residual measure of operational risk that is quite comprehensive. Section VII tests for the presence and significance of cyclicality in our new operational risk measures. Section VIII runs a battery of robustness checks based on conditional VaR measures, alternative distributions, and Monte Carlo simulation. Section IX concludes.

\section{Database}

We analyze catastrophic risk using a sample comprised of financial intermediaries. We limit our study of catastrophic risk to financial institutions in order to define a relatively homogenous group of firms that have broad risk exposures. Financial intermediaries maintain risk inventories as a normal course of conducting business - making markets, underwriting securities and holding portfolios comprised of financial

policy goal. Therefore, value at risk measures that focus on the lower tails of the return distribution are important determinants of bank capital requirements.

${ }^{4}$ Kashyap and Stein (2004) discuss the design of socially optimal capital regulations.

${ }^{5}$ Top-down models of operational risk calculate the overall cost to the firm of operational loss events, whereas bottomup models analyze the risk factors and costs inherent in the individual steps of a production process. Allen, Boudoukh and Saunders (2004) note that whereas bottom-up models may be appropriate for the purposes of risk diagnostics and design of internal managerial controls, top-down models may be effective in estimating economic capital requirements. Currie (2004) calls for the concurrent use of both top-down and bottom-up models in order to estimate operational risk capital requirements.

${ }^{6}$ It is unlikely that employees will volunteer information about operational risk events resulting from human errors and inadequate behavior. This is indicated by the BIS Loss Data Collection Exercise operational risk database that contains 
securities. Thus, we believe that a sample of financial institutions offers the best opportunity to observe a wide range of risk exposures, thereby making it possible to decompose catastrophic risk into its components.

Although financial intermediaries have similar characteristics, they are not completely homogenous. For example, banks differ somewhat from insurance companies and from broker/dealers. ${ }^{7}$ We construct our sample by searching CRSP for all firms traded on either the NYSE, AMEX or Nasdaq that had primary SIC codes of 6XXX over the time period from April 1973 to June $2003 .{ }^{8}$ We obtain monthly data (including dividends) from CRSP, resulting in a total of 209,627 observations of monthly equity returns. ${ }^{9}$ We define the catastrophic risk tail of the monthly return distribution to be those returns in the lowest $10 \%$ of each of the monthly cross sections of observations. In Section II, we perform our analysis on those lower tail observations only, thereby limiting our analysis to 20,978 observations. In Section III, we estimate the entire distribution for financial institutions' monthly equity returns.

The effect of diversification in risk reduction is quite apparent in comparisons of the distribution of SIC codes in the lower tail of the return distribution to the entire distribution comprised of all monthly equity returns on financial institutions. Holding companies (SIC code 67, which includes bank holding companies and mutual funds) represent $48 \%$ of the entire sample, but only $39 \%$ of the observations in the lower return tail of equity returns. Moreover, depository institutions (SIC code 60) have relatively less downside risk exposure than other financial institutions (comprising $20 \%$ of the lower tail observations, but $25 \%$ of the entire database), perhaps as a result of constraining banking regulations, such as minimum capital requirements, as well as access to the governmental safety net in the form of deposit insurance and lender of last resort privileges. In contrast, nondepository credit institutions (SIC code 61) were more heavily represented in the lower tail of equity returns (comprising $9 \%$ of the observations) than in the entire sample (comprising $5 \%$ of the observations). This may reflect the periodic upheavals in the mortgage banking business in the U.S. Other classifications that experienced relatively greater amounts of downside risk over the sample period were real estate firms (SIC code 65 , comprising $9 \%$ of the tail observations, but only $5 \%$

only $3.3 \%$ of the total loss events reported in the "internal fraud" category. See Kalhoff and Haas (2004) and Hass and Kaiser (2004) for a discussion of the insufficiency of loss data for the quantification of operational risk.

7 These lines of distinction have become somewhat blurred by the passage of the Gramm-Leach-Bliley Act of 1999 which permits consolidation of banking, insurance and securities activities into a single financial holding company. In our empirical analysis, we present results for all financial institutions and also distinguish different types of financial intermediaries by their regulatory and market structure environments.

${ }^{8}$ Although we obtain 560,038 monthly returns from CRSP over the period January 1973 - December 2003, an inadequate number of observations available in the COMPUSTAT database reduced our sample period from April 1973 to June 2003. The final number of observations in our database is reduced to 209,627 , predominately because of missing values for assets, net income, sales, as well as the lack of 50 months of continuous monthly returns, all required for the estimation of operational risk in Section VI. However, we have also estimated catastrophic risk distributions using the entire sample of observations over the period of 1973-2001, with similar results (available from the authors upon request) to those presented in this paper. We use a monthly sampling frequency because of the unavailability of most macroeconomic data at shorter frequency intervals. 
of the entire sample), security and commodity brokers (SIC code 62, comprising $6 \%$ of the tail observations, but only $3 \%$ of the entire sample) and insurance companies (SIC code 63, comprising 14\% of the tail observations, but only $12 \%$ of the entire sample).

\section{Estimating Catastrophic Risk Using the Generalized Pareto Distribution}

Catastrophic risk may be generated by extreme shifts in interest rates, exchange rates, equity prices, commodity prices, credit quality or operational performance. Thus, catastrophic risk contains elements of market risk, credit risk and operational risk. In this section and in Section III, we focus on catastrophic risk, whatever its source. Subsequently, in Section VI, we decompose catastrophic risk into its market risk, credit risk and operational risk components and analyze the cyclical effects in the operational risk (residual) component.

\section{A. Generalized Pareto Distribution (GPD):}

Extremes are generally defined as excesses over a high or low threshold, and can be modeled by the generalized Pareto distribution (GPD) of Pickands (1975). This paper concentrates on the lower (left) tail of the return distribution, and obtains the extremes from the cross-section of stock returns for each month from April 1973 to June 2003. ${ }^{10}$ More specifically, extreme returns are measured by the $10 \%$ left tail of the empirical distribution of stock returns $r$.

Let us call $f(r)$ the probability density function (pdf) and $F(r)$ the cumulative distribution function (cdf) of $r$, which can take values between $l$ and $u{ }^{11}$ First, we choose a low threshold $l$ so that all $r_{i}<l<0$ are defined to be in the negative tail of the distribution, where $r_{1}, r_{2}, \ldots, r_{n}$ are a sequence of stock returns. Then we denote the number of exceedances of $l$ (or stock returns lower than $l$ ) by

$$
N_{l}=\operatorname{card}\left\{i: i=1, \ldots, n, r_{i}<l\right\},
$$

and the corresponding excesses by $M_{1}, M_{2}, \ldots, M_{N_{l}}$. The excess distribution function of $r$ is given by:

$$
F_{l}(y)=P(r-l \geq y \mid r<l)=P(M \geq y \mid r<l), \quad y \leq 0
$$

Using the threshold $l$, we now define the probabilities associated with $r$ :

$$
\begin{gathered}
P(r \leq l)=F(l) \\
P(r \leq l+y)=F(l+y)
\end{gathered}
$$

where $y<0$ is an exceedence of the threshold $l$. Finally, let $F_{l}(y)$ be given by

\footnotetext{
9 To check for the possibility of window dressing of quarter-end and year-end data, as found in Allen and Saunders (1992), we constructed our own monthly returns using mid-month to mid-month equity prices. Our results were quite similar to those obtained from the CRSP monthly returns; therefore, we do not report them here.

${ }^{10}$ Campbell, Lettau, Malkiel and Xu (2001), Goyal and Santa-Clara (2003), and Bali, Cakici, Yan, and Zhang (2003) measure average stock risk and average idiosyncratic risk in each month as the cross-sectional equal-weighted or valueweighted average of the variances of all the stocks traded in that month. Similarly, we use the cross-section of stock returns to estimate value at risk for each month from April 1973 to June 2003 in order to identify extreme tail risk events that may never occur in the life cycle of an individual firm.
} 


$$
F_{l}(y)=\frac{F(l)-F(l+y)}{F(l)}
$$

We thus obtain the $F_{l}(y)$, the conditional distribution of how extreme a $r_{i}$ is, given that it already qualifies as an extreme. Pickands (1975) shows that $F_{l}(y)$ will be very close to the generalized Pareto distribution $\mathrm{G}_{\min , \xi}$ in equation (6) if $l$ is a low threshold:

$$
G_{\min , \xi}(M ; \mu, \sigma)=\left[1+\xi\left(\frac{\mu-M}{\sigma}\right)\right]^{-1 / \xi}
$$

where $\mu, \sigma$, and $\xi$ are the location, scale, and shape parameters of the GPD, respectively. The shape parameter $\xi$, called the tail index, reflects the fatness of the distribution (i.e., the weight of the tails), whereas the parameters of scale $\sigma$ and of location $\mu$ represent the dispersion and average of the extremes, respectively. ${ }^{12}$

Two parametric approaches are commonly used to estimate the extreme value distributions: (1) the maximum likelihood method which yields parameter estimators which are unbiased, asymptotically normal, and of minimum variance, and (2) the regression method which provides a graphical method for determining the type of asymptotic distribution. ${ }^{13}$ In this paper the maximum likelihood method is used to estimate catastrophic and operational risk parameters.

Suppose that the generalized extreme value distribution for the minima, $G_{\min }(\Phi ; x)$, has a density function $g_{\text {min }}(\Phi ; x)$, where $\Phi=(\xi, \mu, \sigma) \in \mathfrak{R} \times \mathfrak{R} \times \mathfrak{R}_{+}$consists of a shape parameter $\xi$, a location parameter $\mu$ and a scale parameter $\sigma$. Then the likelihood function based on the data for the minimum variable $M_{T}=\left(M_{1}, M_{2}, \ldots, M_{T}\right)$ is given by

$$
L\left(\Phi ; M_{T}\right)=\prod_{i=1}^{T} g_{\min }\left(\Phi ; M_{i}\right)
$$

Denote the log-likelihood function by $l\left(\Phi ; M_{T}\right)=\ln L\left(\Phi ; M_{T}\right)$. The maximum likelihood estimator (MLE) for $\Phi$ then equals

$$
\hat{\Phi}_{T}=\arg \max _{\Phi \in \Theta} l\left(\Phi ; M_{i}\right)
$$

where $\hat{\Phi}_{T}=\hat{\Phi}_{T}\left(M_{1}, M_{2}, \ldots, M_{T}\right)$ maximizes $l\left(\Phi ; M_{T}\right)$ over an appropriate parameter space $\Theta$.

The generalized Pareto distribution presented in (6) has a density function for the minima,

${ }^{11}$ For example, a random variable distributed as the normal gives $l=-\infty$ and $u=+\infty$.

12 The generalized Pareto distribution presented in equation (6) nests the Pareto distribution, the uniform distribution, and the exponential distribution. The shape parameter, $\xi$, determines the tail behavior of the distributions. For $\xi>0$, the distribution has a polynomially decreasing tail (Pareto). For $\xi=0$, the tail decreases exponentially (exponential). For $\xi$ $<0$, the distribution is short tailed (uniform).

${ }^{13}$ Details and presentation of alternative statistical estimation methods can be found in Leadbetter, Lindgren, and Rootzen (1983), Resnick (1987), Embrechts, Kluppelberg, and Mikosch (1997), Longin (1996), and Bali (2003). 


$$
g_{\min }(\Phi ; x)=\left(\frac{1}{\sigma}\right)\left[1+\xi\left(\frac{\mu-M}{\sigma}\right)\right]^{-\left(\frac{1+\xi}{\xi}\right)}
$$

which yields the log-likelihood function:

$$
\operatorname{LogL}_{\mathrm{GPD}}=-T \ln \sigma-T\left(\frac{1+\xi}{\xi}\right) \sum_{i=1}^{T} \ln \left(1+\xi\left(\frac{\mu-M_{i}}{\sigma}\right)\right)
$$

Differentiating the log-likelihood function in (10) with respect to $\mu, \sigma$, and $\xi$ yields the first-order conditions of the maximization problem. Clearly, no explicit solution exists to these nonlinear equations, and thus numerical procedures or search algorithms are required.

Figures 1A, 1B, and 1C, respectively, present the location, scale, and shape parameter estimates (denoted $\mu-G P D, \sigma-G P D$ and $\xi-G P D$, respectively) obtained for our sample of financial institutions. For example, Figure 1A graphs the monthly location parameters of the GPD over the April 1973 to June 2003 period. The lowest value of the location parameter of the catastrophic risk tail was -0.37 and was obtained in October 1987, the month of the market crash. The highest monthly location parameter value was 0.07 for January 1975, the start of the recovery from the deep 1973-1974 recession. The scale parameter (shown in Figure 1B) was minimized at a value of 0.01 during the months of August 1973 and March 1979. The first date corresponds to the introduction of options trading on the Chicago Board of Trade and the second date coincides with the passage of the Depository Institutions Deregulation and Monetary Control Act (DIDMCA) which lifted interest rate ceilings, increased deposit insurance coverage to $\$ 100,000$, allowed banks to offer savings accounts paying market interest rates, expanded lending powers for thrift institutions, and set uniform reserve requirements for state and nationally chartered banks. Both the introduction of risk management through options trading on organized exchanges and the DIDMCA were heralded as revolutionary improvements in the economic and regulatory environment governing financial intermediation. On the other hand, the scale parameter was maximized (at 0.28) for the month of December 1990. This coincided with the passage of the Basel capital accords, the first risk-adjusted international bank capital requirements. Finally, Figure 1C plots the monthly tail-thickness parameter, which shows that catastrophic risk is characterized by fat tails since the estimated shape parameters are positive for most months.

\section{Estimating Catastrophic Risk Using the Skewed Generalized Error Distribution}

In Section II, we focus on the lower tail of the return distribution. That is, we define catastrophic risk based on the lowest $10 \%$ of all monthly equity returns for financial institutions during any month over the period from April 1973 to June 2003. In this section, we investigate the shape of the entire return distribution. Thus, the results here place catastrophic risk into the context of the entire probability distribution of monthly cross-sectional equity returns for financial intermediaries. 
In order to depict the range of all observed monthly equity returns, we must make some assumptions about the presumed shape of the equity return distribution. We start with the simplest and most restrictive assumption - normality. Then we proceed to a general distribution, the Skewed Generalized Error Distribution (SGED), thereby permitting the estimation of four distributional moments - mean, standard deviation, skewness and kurtosis. We submit these distributional assumptions to statistical tests (likelihood ratio test) of the null hypothesis (normality) against the SGED assumption. Monthly likelihood ratio tests strongly reject the normality assumption at the 1\% significance level for almost all months from April 1973 to June $2003 .^{14}$

\section{A. Skewed Generalized Error Distribution (SGED):}

Subbotin (1923) introduces the Generalized Error Distribution (GED) as special cases of Laplace, normal, and uniform distributions. The symmetric GED density is given by equation (11):

$$
f_{v}\left(\eta_{t}\right)=\frac{v \exp \left[(-1 / 2)\left|\eta_{t} / \Pi\right|^{v}\right]}{\Pi 2^{[(v+1) / v]} \Gamma(1 / v)}
$$

where $r_{t}$ is the return at time $t, \eta_{t}=\frac{r_{t}-\mu}{\sigma}$ is the standardized return at time $t, \quad \Gamma(a)=\int_{0}^{+\infty} x^{a-1} e^{x} d x$ is the gamma function, $\Pi=\left[\frac{2^{(-2 / v)} \Gamma(1 / v)}{\Gamma(3 / v)}\right]^{1 / 2}$, and $v>0$ is the degrees of freedom or tail-thickness parameter. For $v=2$, the GED yields the normal distribution, while for $v=1$ it yields the Laplace or the double exponential distribution. If $v<2$, the density has thicker tails than the normal, whereas for $v>2$ it has thinner tails.

The GED is used by Box and Tiao (1962) to model prior densities in Bayesian estimation, Nelson (1991) to model the distribution of stock market returns, and Hsieh (1989) to model the distribution of exchange rates. Bali and Theodossiou (2003) introduce an asymmetric (or skewed) version of the GED. The Skewed Generalized Error Distribution (SGED) adds an additional moment, skewness, to the GED formulation. The probability density function for the SGED is

$$
f\left(r_{t} ; \mu, \sigma, k, \lambda\right)=\frac{C}{\sigma} \exp \left(-\frac{1}{\left[1+\operatorname{sign}\left(r_{t}-\mu+\delta \sigma\right) \lambda\right]^{k} \theta^{k} \sigma^{k}}\left|r_{t}-\mu+\delta \sigma\right|^{k}\right)
$$

where $\quad C=k /(2 \theta \Gamma(1 / k)), \quad \theta=\Gamma(1 / k)^{0.5} \Gamma(3 / k)^{-0.5} S(\lambda)^{-1}, \quad \delta=2 \lambda A S(\lambda)^{-1}, S(\lambda)=\sqrt{1+3 \lambda^{2}-4 A^{2} \lambda^{2}}$, $A=\Gamma(2 / k) \Gamma(1 / k)^{-0.5} \Gamma(3 / k)^{-0.5}, \mu$ and $\sigma$ are the mean and standard deviation of returns $r_{t}, \lambda$ is a skewness parameter, sign is the sign function, and $\Gamma($.$) is the gamma function. The scaling parameters k$ and $\lambda$ obey

\footnotetext{
${ }^{14}$ We do not reject normality in only 19 out of 363 months, mostly during 1973-1974. To save space we do not present the likelihood ratio test results. They are available upon request.
} 
the following constraints $k>0$ and $-1<\lambda<1$. The parameter $k$ controls the height and tails of the density function and the skewness parameter $\lambda$ controls the rate of descent of the density around the mode of $r$, where mode $(r)=\mu-\delta \sigma$. In the case of positive skewness $(\lambda>0)$, the density function is skewed to the right. This is because for values of $r<\mu-\delta \sigma$, the return variable $r$ is weighted by a greater value than unity and for values of $r>\mu-\delta \sigma$ by a value less than unity. The opposite is true for negative $\lambda$. Note that $\lambda$ and $\delta$ have the same sign, thus, in case of positive skewness $(\lambda>0)$, the mode $(r)$ is less than the expected value of $r$. The parameter $\delta$ is Pearson's skewness $[\mu-\operatorname{mode}(r)] / \sigma=\delta$.

The SGED distribution reduces to the GED for $\lambda=0$, the Laplace distribution for $\lambda=0$ and $k=1$, the normal distribution for $\lambda=0$ and $k=2$, and the uniform distribution for $\lambda=0$ and $k=\infty$.

The SGED parameters are estimated by maximizing the log-likelihood function of $r_{t}$ with respect to the parameters $\mu, \sigma, k$, and $\lambda$ :

$$
\log L(\mu, \sigma, k, \lambda)=n \ln C-n \ln \sigma-\frac{1}{\theta^{k} \sigma^{k}} \sum_{t=1}^{n}\left(\frac{\left|r_{t}-\mu+\delta \sigma\right|^{k}}{\left[1+\operatorname{sign}\left(r_{t}-\mu+\delta \sigma\right) \lambda\right]^{k}}\right)
$$

where $C, \theta$, and $\delta$ are defined below equation (12), sign is the sign of the residuals $\left(r_{t}-\mu+\delta \sigma\right)$, and $n$ is the sample size.

We estimate the entire return distribution under the two alternative assumptions - the normal and the SGED - but the empirical results are presented only for SGED density to preserve space. Figure 2 presents the monthly parameter estimates for the SGED consisting of four moments (mean plotted in Figure 2A, standard deviation in Figure 2B, skewness in Figure 2C and kurtosis in Figure 2D). We find a similar pattern of volatility in the moments of the SGED as shown in Figure 1 for the GPD.

\section{Catastrophic Value at Risk (VaR) Estimates Using the GPD and SGED}

The traditional $\mathrm{VaR}$ models assume that the probability distribution of log-price changes (logreturns) is normal. However, our results reject that hypothesis. Thus, we must use alternative VaR models based on the GPD and SGED parameters.

In continuous time diffusion models, $(\log )$-stock price movements are described by the following stochastic differential equation,

$$
d \ln P_{t}=\mu d t+\sigma d W_{t}
$$

where $P_{t}$ is the price level at time $t, W_{t}$ is a standard Wiener process with zero mean and variance of $d t, \mu$ and $\sigma$ are the drift and diffusion parameters. In discrete time, equation (14) yields a return process:

$$
\ln P_{t+\Delta}-\ln P_{t} \equiv r_{t}=\mu \Delta t+\sigma z \sqrt{\Delta t}
$$

where $\Delta t$ is the length of time interval in which the discrete time data are recorded and $\Delta W_{t}=z \sqrt{\Delta t}$ is the Wiener process with zero mean and variance of $\Delta t$. 
The critical step in calculating VaR is the estimation of the threshold point defining what variation in returns $r_{t}$ is considered to be extreme. Let $\alpha$ be the probability that $r_{t}$ is less than the threshold $\vartheta$. That is,

$$
\operatorname{Pr}\left(r_{t}<\vartheta\right)=\operatorname{Pr}\left(z<a=\frac{\vartheta-\mu \Delta t}{\sigma \sqrt{\Delta t}}\right)=\alpha
$$

where $\operatorname{Pr}(\cdot)$ is the underlying probability distribution. In the traditional VaR model, $\alpha=1 \%, a=-2.326$,

$$
\vartheta_{\text {Normal }}=\mu \Delta t-2.326 \sigma \sqrt{\Delta t} \text {. }
$$

The risk manager, who has exposure to a risk factor $r_{t}$, needs to know how much capital to put aside to cover at least the fraction $1-\alpha$ of daily losses during a year. For this purpose, the risk manager must first determine a threshold $\vartheta$ so that the event $\left(r_{t}<\vartheta\right)$ has a probability $\alpha$ under $\operatorname{Pr}(\cdot){ }^{15}$ The standard approach does this by using an explicit distribution that is generally assumed to be the normal distribution. An alternative approach is to use a cumulative probability distribution $F(\vartheta)$ based on one of the extreme value and flexible probability distributions, and then solve for $\vartheta$ to obtain the threshold, i.e.,

$$
\vartheta=F^{-1}(1-\alpha) \text {. }
$$

As shown in Bali (2003), the GPD distribution yields the following VaR threshold: ${ }^{16}$

$$
\vartheta_{G P D}=\mu+\left(\frac{\sigma}{\xi}\right)\left[\left(\frac{\alpha N}{n}\right)^{-\xi}-1\right]
$$

where $n$ and $N$ are the number of extremes and the number of total data points, respectively. Once the location $(\mu)$, scale $(\sigma)$, and shape $(\xi)$ parameters of the GPD distribution are estimated one can find the VaR threshold, $\vartheta_{G P D}$, based on the choice of confidence level $(\alpha)$.

There is substantial empirical evidence that the distribution of stock returns shows high peaks, fat tails and more outliers on the left tail. To account for skewness and kurtosis in the data, we use the skewed generalized error distribution (SGED) that takes into account the non-normality of returns and relatively infrequent events. As shown in Bali and Theodossiou (2003), an alternative approach to calculating VaR is based on the lower tail of the SGED distribution. Specifically, we estimate the parameters of the SGED density $(\mu, \sigma, k, \lambda)$ using monthly returns and then find a specific percentile of the estimated distribution. Assuming that $r_{t} \sim f_{k, \lambda}(z)$ follows an SGED density, parametric VaR is the solution to:

$$
\int_{-\infty}^{\vartheta_{S G E D}(\alpha)} f_{k, \lambda}(z) d z=\alpha
$$

${ }^{15}$ Basak and Shapiro (2001) show that VaR-based risk management may induce managers to incur larger losses, while still complying with a VaR constraint, by insuring against intermediate-loss states and incurring large losses in the worst states of the world.

${ }^{16}$ For alternative extreme value approaches to estimating VaR, see Longin (2000) and McNeil and Frey (2000). 
where $\vartheta_{\text {SGED }}(\alpha)$ is the VaR threshold based on the SGED density with a loss probability of $\alpha$. Equation (20) indicates that value at risk can be calculated by integrating the area under the probability density function of the SGED distribution. Equation (20) can also be viewed as $\vartheta_{S G E D}=\mu \Delta t+a \sigma \sqrt{\Delta t}$, where $\mu$ and $\sigma$ are the mean and standard deviation parameters of the SGED density and $a$, which depends on the higher moments (e.g., skewness and kurtosis) of the SGED, is the cut-off for the standardized cdf associated with probability $1-\alpha$, i.e., $F(a)=1-\alpha$.

Using equations (19) and (20), we estimate the monthly Value at Risk (VaR) at the 99\% confidence intervals (1\% VaR) for the GPD and SGED parameters. Figure 3 compares the VaR results using the two methodologies. Figure 3A plots the two VaR estimates, whereas Figure 3B deducts the GPD estimate from the SGED estimate. The VaR estimates are quite similar throughout the sample period; on average, the difference between the SGED 1\% VaR and the GPD 1\% VaR shown in Figure 3B is insignificant from zero. ${ }^{17}$ However, there are several outliers (during the months of January 1975 and January 1992) that generally correspond to outlier GPD 1\% VaR estimates.

\section{Measuring the Significance of Cyclical Factors in Catastrophic Risk Measures}

To test for cyclicality in the catastrophic risk measures defined in Section IV, we gathered monthly data on macroeconomic, systemic risk, and regulatory factors from a wide variety of data sources. ${ }^{18}$ The variables can be broadly classified into seven categories: macroeconomic (including GDP, unemployment statistics, the University of Michigan survey on consumer sentiment, business bankruptcies, industrial production and NBER-marked recessions), foreign exchange rates (for the major currencies - the Japanese

yen, the German mark and the British pound sterling in terms of US dollars), ${ }^{19}$ equity market indices (for Canada, France, Italy, Germany, Japan, the UK and the US), consumer price indices (for Japan, Germany, the UK and the US), interest rates (for long and short government bonds, Aaa-rated corporate bonds and Baarated corporate bonds), money supply figures (M2 for Japan, Germany, the EU, the UK and the US), and regulatory dummy variables (for the passage of the Depository Institutions Deregulatory and Monetary Control Act in March 1980, the FDIC Improvement Act in December 1991, the first Basel Capital Accord in December 1992, the Riegle-Neal Interstate Banking and Branching Efficiency Act in September 1994, and

\footnotetext{
${ }^{17}$ Comparisons using the $0.5 \%, 2.5 \%$, and $5 \%$ VaR yield similar results to those shown in Figure 3 .

${ }^{18} \mathrm{We}$ measure the impact of economic and financial factors directly on monthly risk profiles. In contrast, there is a literature that incorporates systemic risk considerations by altering the variance-covariance matrix underlying returns. However, this may jeopardize the properties (e.g., invertibility) of the historical variance covariance matrix. See Kyle and Xiong (2001), Longin and Solnik (2001), Kodres and Pritzker (2002), and Rigobon and Forbes (2002).

${ }_{19}$ The monthly time series observations of DM/US are not available after January 1999 because of the adoption of the euro. We incorporate the Euro/US dollar exchange rate into the DM/US dollar exchange rate series after January 1999.
} 
the Gramm-Leach-Bliley Act in November 1999). ${ }^{20}$ Panels A and B of Table 1 provide the source of data and the descriptive statistics for each of the 43 macroeconomic, cyclical and regulatory factors.

\section{A. Modeling Cyclical Components in the Catastrophic Risk Measures:}

We utilize the results from Sections II and III to test for cyclicality in our catastrophic risk measures. That is, in Section II we estimate catastrophic risk using the extreme value theory with the generalized Pareto distribution (GPD) for the lowest $10 \%$ of equity returns for financial institutions in each month of our sample period 1973-2003. That analysis generates three catastrophic risk estimates: the location parameter (the mean of the extremes), the scale parameter (related to the standard deviation of the extremes) and the shape or tail index parameter (measuring tail-thickness of the GPD). Hereinafter we denote these three monthly parameters respectively as $\mu-G P D, \sigma-G P D$, and $\xi-G P D .^{21}$

In Section III, we estimate the entire return distribution using the Skewed Generalized Error Distribution (SGED), after rejecting the hypothesis of normality for almost all months in our sample. The SGED estimation generates four monthly parameter measures: mean, standard deviation, kurtosis and skewness, hereinafter denoted $\mu-S G E D, \sigma-S G E D, \xi-S G E D$, and $\lambda-S G E D$, respectively. Using the derivations based on the GPD and SGED parameters, we define the catastrophic Value at Risk (VaR) at the 1\% level as VaR $1 \%-G P D$ and $V a R 1 \%-S G E D$, respectively. ${ }^{22}$

To investigate cyclicality, we calculate correlation coefficients for each of the 43 macroeconomic variables (listed in Table 1) with the catastrophic risk measures. ${ }^{23}$ Table 2 shows the correlation coefficients between the macroeconomic variables and the four parameters from the GPD estimation ( $\mu-G P D, \sigma-G P D, \xi-$

\footnotetext{
${ }^{20}$ Although many other regulatory regime shifts occurred over the period 1973-2003, these five were viewed to be the most significant in terms of their impact on catastrophic risk in the financial services industry. The DIDMCA removed interest rate ceilings on deposits, authorized interest-bearing checking accounts (NOW and MMDA accounts), introduced uniform reserve requirements, increased deposit insurance coverage and expanded thrift powers. The FDICIA introduced prompt corrective action to require regulators to intervene when bank capital falls below certain thresholds, phased in risk-based deposit insurance premiums, limited "too big to fail" bailouts and forbearance by regulators, and extended federal regulation over foreign banks. The Basel Capital Accord created an internationally level playing field of capital requirements that were risk-adjusted and that included a capital charge for off-balance sheet activities. The Interstate Banking Act permitted bank holding companies to expand across state lines. The GLBA removed the Glass-Steagall Act restrictions on consolidation of banking, insurance and securities activities into a single holding company, thereby creating the financial holding company structure.

${ }^{21}$ Bali and Neftci (2003) indicate that the mean of the GPD can be measured by the estimated $\mu$-GPD location parameter. They also show that the kurtosis of the extremes is largely determined by the estimated $\xi-G P D$ and the standard deviation is a function of both the $\sigma-G P D$ and the $\xi$-GPD parameters.

${ }^{22}$ For ease of exposition, all VaR measures are multiplied by -1 before running our regressions and computing correlations, even though the original VaR values are negative since they are obtained from the left tail of the return distribution.

${ }^{23}$ We report the results of the univariate analysis because of multicollinearity problems across the 43 macroeconomic variables. However, using either a Stepwise regression approach or OLS on a subset of macroeconomic variables, we find evidence of considerable cyclicality in the catastrophic risk measures. Indeed, the adjusted R-squares for the Stepwise regression model with all 43 macroeconomic variables and VaR1\%-GPD (VaR1\%-SGED) as the dependent variable is $52.17 \%(55.81 \%)$.
} 
$G P D$, and $V a R 1 \%-G P D)$, and Table 3 shows the correlation coefficients for the five risk parameters estimated using the SGED ( $\mu-S G E D, \sigma-S G E D, \xi-S G E D, \lambda-S G E D$, and VaR1\%-SGED). In both tables, we find evidence consistent with significant levels of cyclicality in catastrophic risk. Comparing Tables 2 and 3 shows that the relationships between both measures of $1 \% \mathrm{VaR}$ and the macroeconomic variables are quite similar, both quantitatively and qualitatively. For example, the positive (significant at the 1\% level) correlation coefficients on the Index of Industrial Production (IndustryIndex variable) of 0.23 for VaR $1 \%$ GPD in Table 2 and 0.19 VaR1\%-SGED in Table 3 suggest that catastrophic risk increases in recessions. Since the industrial production index is a leading indicator, peaks in the index indicate turning points in the business cycle. Thus, the positive coefficients on the industrial production index variable for the VaR regressions are consistent with evidence of forward-looking procyclicality in catastrophic VaR, such that downturns in the economy coincide with high levels of the index of industrial production, thereby signaling an increase in value at risk. A similar forward-looking procyclicality is shown in the negative and significant (at the $1 \%$ level) correlation coefficients for the US unemployment rate (Usunempl variable) of -0.23 for VaR $1 \%-G P D$ in Table 2 and -0.15 VaR1\%-SGED in Table 3, suggesting that catastrophic VaR increases when unemployment rates decrease, signaling the end of an economic boom. US GDP figures are also positively correlated with catastrophic VaR (correlation coefficient of $0.25(0.20)$ in Table 2 (Table 3) for VaR1\%-GPD (VaR1\%-SGED), both significant at the 1\% level. Moreover, the positive and significant (at the $1 \%$ level) correlations between catastrophic VaR (both VaR $1 \%-G P D$ and VaR1\%-SGED) and all country stock market indices (for Canada, FPS6CA; for France, FPS6FR; for Germany, FPS6WG; for Italy, FPS6IT; for Japan, FPS6JP; for the UK, FPS6UK; and for the US, SPINDX), further suggests forward-looking procyclicality in catastrophic risk as the value at risk increases during stock market booms. The procyclical nature of banking activity is further demonstrated by the positive and significant (at the $1 \%$ level) correlation coefficients on the RsvAsset variable for both VaR1\%-GPD (0.46 in Table 2) and VaR1\%-SGED (0.35 in Table 3), suggesting that value at risk increases when bank reserves increase. Thus, banks retrench on their lending activity when risk levels increase, thereby exacerbating economic downturns.

The correlation coefficients presented in Tables 2 and 3 indicate a significant (at the 1\% level) negative relationship between catastrophic VaR and the euro/US and yen/US exchange rates. Moreover, all country price index variables (for Japan, $C P I J P$; for the UK, CPI_UK; for the US, CPI_US; and for Germany, CPI_G) display a positive and significant (at the $1 \%$ level) correlation with both estimates of catastrophic VaR. Declines in interest rates (both short term and long term, and across countries) correspond to increases in catastrophic value at risk, as reflected in the negative correlation coefficients shown in Tables 2 and 3 for these variables.

The procyclicality found in the catastrophic $\mathrm{VaR}$ is also evidenced in the distributional risk parameters. For example, the positive and significant (at the $5 \%$ level or better) correlation coefficients on 
the mean variables ( 0.12 for $\mu-G P D$ in Table 2 and 0.16 for $\mu-S G E D$ in Table 3 ) for the US unemployment variable suggest a negative (leftward) shift in the return distribution when decreased unemployment levels signal the end of an economic upturn, consistent with the forward-looking procyclicality shown for catastrophic value at risk.

The regulatory environment also plays a role in determining the financial firms' catastrophic risk exposures. For example, passage of the Depository Institutions Deregulatory and Monetary Control Act (DIDMCA) of 1980, the FDIC Improvement Act (FDICIA) of 1991 and the Gramm-Leach-Bliley Act (GLBA) of 1999 are all consistent with a significant (at the 5\% level or better) increase in 1\% VaR measured using both the GPD and the SGED approaches, demonstrating the risk inducing impact of regulatory policy changes.

\section{Measuring Operational Risk}

Before we estimate operational risk, we must first define it; something easier said than done. The definitions range from the very narrow (regulatory approach) to extremely broad classifications. For example, Kingsley et al. (1998, p.3) define operational risk to be the "risk of loss caused by failures in operational processes or the systems that support them, including those adversely affecting reputation, legal enforcement of contracts and claims." Often this definition includes both strategic risk and business risk. That is, operational risk arises from breakdowns of people, processes and systems (usually, but not limited to technology) within the organization. Strategic and business risk originate outside of the firm and emanate from external causes such as political upheavals, changes in regulatory or government policy, tax regime changes, mergers and acquisitions, and changes in market conditions.

However, the Basel Committee on Banking Supervision excludes strategic and business risk from the definition proposed in the New Capital Accord adopted in June 2004. ${ }^{24}$ That is, BIS (September 2001) defines operational risk to be "the risk of loss resulting from inadequate or failed internal processes, people and systems or from external events." Explicitly excluded from this definition are systemic risk, strategic and reputational risks, as well as all indirect losses or opportunity costs, which may be open-ended and huge in size compared to direct losses.

We utilize the more expansive definition of operational risk. Indeed, we define operational risk as a residual measure. After all the identifiable sources of risk (credit risk, interest rate risk, exchange rate risk, equity price risk, etc.) are accounted for, the remainder is defined as operational risk. This sidesteps the difficult problem of modeling business activities on a micro level. ${ }^{25}$

\footnotetext{
${ }^{24}$ In October 2003, the SEC adopted a definition of operational risk for investment banks and broker-dealers that is even narrower than the Basel II definition in that it omits legal risk. See Currie (2004).

${ }^{25}$ Ebnother et al. (2003) perform a case study that expends considerable resources to model 103 production processes, but can only explain a small portion of the firm's VaR, despite the high cost of defining and maintaining data about the operational processes. Chernobai and Rachev (2004) use a proporietary loss database obtained from a European bank
} 
A comprehensive measure of operational risk is appropriate for the purposes of computation of economic capital requirements. Operational risk events can be divided into high frequency/low severity (HFLS) events that occur regularly, in which each event individually exposes the firm to low levels of losses. In contrast, low frequency/high severity (LFHS) operational risk events are quite rare, but the losses to the organization are enormous upon occurrence. An operational risk measurement model must incorporate both HFLS and LFHS risk events. However, HFLS operational risk events are priced and can be insured, either through purchase of external insurance policies or through self-insurance. Thus, it is the LFHS operational risk events that are the focus of both economic and regulatory capital. Because of moral hazard considerations, these extreme risk events are generally uninsurable externally. Moreover, they cannot be selfinsured because a single LFHS operational risk event is typically sufficient to force the financial institution into insolvency. Thus, the narrow Basel definition of operational risk that limits attention to HFLS events is inconsistent with the function of capital as the cushion against extreme tail risk events. Moreover, operational loss databases tend to suffer from an under-representation of LFHS risk events. Haas and Kaiser (2004) note that LFHS events are, by definition, much less likely to occur, are often kept confidential and therefore are unreported, and may be misclassified as credit or market risk losses, thereby biasing estimates of $\mathrm{VaR}$ obtained using operational loss databases. ${ }^{26}$ Furthermore, databases generated through data-sharing agreements across firms (as in the BIS Loss Data Collection Exercise and the proprietary Operational Riskdata eXchange) must also be scaled to fit the size and business mix of different companies for the data to be applicable to estimation of operational risk for a given firm. However, this is very difficult to accomplish given the poor quality of operational loss databases.

To avoid these data problems, we estimate the more comprehensive, residual operational risk measure for each financial institution using a monthly time series of equity returns over the period 19732003 for all firms in our sample with at least 50 consecutive monthly equity returns. ${ }^{27}$ For each of these firms, we estimated the following OLS regression: ${ }^{28}$

$$
r_{t}=\alpha_{0, t}+\alpha_{1, t} \Delta x_{1 t}+\ldots+\alpha_{22, t} \Delta x_{22 t}+\beta_{t} r_{t-1}+\sum_{i=1}^{4} \gamma_{i, t} F F_{i t}+\sum_{i=1}^{3} \pi_{i, t} R_{i t}+\varepsilon_{t}
$$

where $r_{t}$ and $r_{t-1}$ are the monthly current and lagged equity returns on each of the financial firms in our sample over the period $t=$ April 1973 through June 2003; $\Delta x_{i t},(i=1,2, \ldots, 22)$, is the first order difference

\footnotetext{
and find evidence of both fat tails and skewness in a bottom-up model of operational risk, consistent with our findings using equity returns in a top-down approach.

${ }^{26}$ Another bias inherent in operational loss databases stems from the minimum loss requirement for inclusion in the database. See Haas and Kaiser (2004) and Kalhoff and Haas (2004) for a discussion of how truncated databases yield biased VaR estimates.

${ }^{27}$ There were 38 firms with only 50 monthly observations. The average number of months for any individual financial firm in our sample was 131. The maximum number was 363 months over the entire sample period of April 1973 - June 2003.

${ }^{28}$ This model is the reduced form of a lagged regression model with an assumed one month lag.
} 
of the 22 variables used to estimate credit risk, interest rate risk, exchange rate risk and market risk; ${ }^{29} F F_{i t}$ represents the three Fama-French (1993) factors (overall excess return on the market, SMB, and HML) and the momentum factor (UMD); ${ }^{30}$ and three alternative industry return factors, $R_{i t}$, representing the average monthly return for each industry sector: depository institutions, insurance companies and securities firms. The equity returns on each of the three industry sectors are determined by dividing the sample of financial firms into three groups: depository institutions (SIC codes 60XX, 66XX and 6712), insurance companies (SIC codes $63 \mathrm{XX}$ and $64 \mathrm{XX}$ ) and securities firms (all other 6XXX-level SIC codes). The $22 \Delta x_{i t}$ variables are taken from the macro variables defined in Table 1 and are grouped by risk source as follows: ${ }^{31}$

Overall Credit Risk Measure:

$\mathrm{R}_{\mathrm{AAA}}-\mathrm{R}_{\mathrm{BBB}}=$ the spread between the $\mathrm{AAA}$ and the $\mathrm{BBB}$ corporate bond yield.

Firm Specific Credit Risk Measures:

Market value of equity/Book value of assets $=1-$ leverage ratio.

Net income/sales.

Log of book value of total assets.

Interest Rate Risk Measures:

$\mathrm{R} 3 \mathrm{MTB}=3$ month US Treasury bill rates.

$\mathrm{R}-10 \mathrm{YTB}=10$ year US Treasury bond rates.

RM1B3S_a_UZ=3 month Euribor rates.

RMGB10Y_a_GY=10 year German Treasury bond rates.

RMBANK_a_JP=Discount rate in Japan.

RMGBL_a_JP=Long Japanese bond rates.

RMGBS_a_UK=91 day UK Treasury bill rates.

RMGBL_a_UK $=10$ year UK Treasury bond rates.

Exchange Rate Risk Measures:

Exgeus=Deutschemark/US dollar exchange rate. ${ }^{32}$

Exukus $=$ British pound/US dollar exchange rate.

Exjpus $=$ Japanese yen/US dollar exchange rate.

Market Risk Measures:

FPS6CA=Equity Index Canada.

FPS6FR=Equity Index France.

FPS6IT=Equity Index Italy.

FPS6JP=Equity Index Japan.

FPS6UK=Equity Index UK.

29 Each variable has 363 monthly observations over the sample period.

30 SMB measures the monthly performance of small stocks relative to big stocks (small minus big), HML measures the monthly equity returns on a portfolio of value stocks relative to growth stocks (high book-to-market minus low bookto-market) and UMD is the momentum factor, measured as the average return on the two highest prior return portfolios minus the average return on the two lowest prior return portfolios. The monthly Fama-French factors and UMD are available on Kenneth French's website at http://mba.tuck.dartmouth.edu/pages/faculty/ken.french/data_library.html.

31 The three firm-specific credit risk measures are taken from quarterly COMPUSTAT.

32 After January 1999, the DM/US dollar exchange rate was replaced by the Euro/US dollar exchange rate by calculating an imputed DM/US dollar exchange rate as follows: (DM/Euro as of December 1998) $\times($ Euro/US\$ as of each month starting in January 1999) = imputed DM/US\$ for each month in the sample period after the adoption of the Euro. 
FPS6WG=Equity Index Germany.

SPINDX=S\&P 500 Index.

The residual term, $\varepsilon_{t}$, from equation (21), is the measure of operational risk used in this analysis. The coefficients on the $\Delta x_{i t}$ terms $\left(\alpha_{i, t}, \beta_{i, t}, \gamma_{i, t}, \pi_{i, t}\right)$ are estimated as time-varying risk measures after the first 50 continuous months of observations. We utilize a rolling window of 50 months in order to estimate the monthly coefficient for each of the 22 risk measures. For example, suppose that a firm has 100 continuous monthly observations. We use the first 50 monthly returns to estimate the residual term in equation (21). Then, we replace the data of the first month with the data of the $51^{\text {st }}$ month, and re-estimate the coefficients from equation (21). After that, we calculate the residual term for the $51^{\text {st }}$ month by plugging the re-estimated coefficient estimates into equation (21). Following the same approach, we keep updating the coefficient estimates and residuals from the $52^{\text {nd }}$ month to the $100^{\text {th }}$ month. ${ }^{33,34}$ We then use the monthly residual operational risk measures derived from equation (21) to re-estimate the tails of the loss distribution.

In the final sample, we have 217,158 observations with the number of firms in any month ranging from 70 to $1,169 .{ }^{35}$ A considerable portion of the raw returns for financial firms can be attributed to a return for operational risk exposure. On average, the ratio of residual (operational risk) to total equity returns is $17.7 \%$, with considerable monthly variance. ${ }^{36}$ This suggests that financial firms have considerable levels of residual operational risk exposure that has been left relatively unmanaged. This may be the result of the lag in the development of operational risk measurement models, as well as the less developed state of the catastrophic and operational risk derivatives market. ${ }^{37}$

\footnotetext{
${ }^{33}$ We perform several robustness checks of this specification: (1) utilizing an 80-month rolling window, reduced the number of observations to 168,520 ; (2) utilizing a 100-month rolling window, reduced the number of observations to 139,669. Although the results (available upon request) were very similar to those presented in the paper, the operational VaR measures tended to be slightly higher using the 80 and 100 month windows. Therefore, the results presented in the paper for operational value at risk can be considered conservative estimates.

34 Since information on macroeconomic and firm-specific variables are not released contemporaneously, we performed an additional robustness check on our model. We reconstituted the database matching CRSP and macroeconomic data with COMPUSTAT data one quarter later. The number of observations fell to 208,420, but there was no impact on our results (available upon request).

${ }^{35}$ We obtained qualitatively similar results when we performed a similar analysis by estimating equation (21) omitting the COMPUSTAT firm specific measures of credit risk. For that analysis, we had a total of 355,586 (rather than $217,158)$ observations.

${ }^{36}$ The range of the ratios is not necessarily between 0 and 1 if, for example, the raw return for a particular monthly equity return is very small or negative whereas the 22 risk variables imply a high positive return, then the residual will be a large negative number, resulting in a ratio with absolute value exceeding one. In computing the mean, we dropped the results for January 2002 and February 2002 (1,692 observations) because of very low monthly average equity returns (driven by two outlier firms) that raised the ratio to unrealistically high levels for these two months.

${ }^{37}$ For a discussion of operational risk measurement and management using derivatives, see Chapter 5 of Allen, Boudoukh and Saunders (2004).
} 
In order to examine the distribution of operational risk across types of financial intermediaries, we measure operational risk for each of the three industry segments defined in equation (21). ${ }^{38}$ The insurance industry absorbed the least amount of operational risk on average over the 1973-2003 period. The average monthly ratio of residual to total equity returns for insurance companies is $10.5 \%$ as compared to $19.4 \%$ for securities firms. In contrast, depository institutions have an average monthly ratio of residual to raw equity returns of $39.4 \%$. This is consistent with moral hazard implications of the government safety net that may induce banks to take on additional risk exposures. In the next sections, we utilize both the GPD and the SGED distributions to examine the tails of our derived operational risk measures.

\section{A. Estimating the Operational Risk Parameters}

We use the methodology presented in Section II to re-estimate the three GPD location, scale and tail thickness parameters (denoted $\mu-O R G P D, \sigma-O R G P D$, and $\xi$-ORGPD, respectively) using the operational risk residuals and then use the methodology in Section IV to define the GPD operational Value at Risk (VaR) at the $1 \%$ level, denoted $V a R 1 \%$-ORGPD. Figure $4 \mathrm{~A}$ compares the $1 \%$ operational VaR measures using the GPD to the catastrophic 1\% VaR measures using the GPD. The plot of the monthly VaR shows that, in a majority of months during the 1973-2003 sample period, the operational value at risk measures are lower (have lower loss levels) than the VaR measures obtained for catastrophic risk. Losses from operational risk events are less than the losses from catastrophic risk events (including all sources of risk) at all probability levels. $^{39}$

Using the monthly residual operational risk measures, we re-estimate the SGED using the methodology described in Section III for operational risk, thereby generating four parameter measures: mean, standard deviation, kurtosis and skewness for operational risk (denoted $\mu$-ORSGED, $\sigma-O R S G E D, \xi$ ORSGED, and $\lambda$-ORSGED, respectively). Using these parameter values, we then estimate the monthly operational 1\% VaR (denoted VaR1\%-ORSGED) and compare with the catastrophic 1\% VaR (denoted VaR $1 \%-S G E D)$. Figure 4B shows that the operational VaR measures are lower than the catastrophic VaR measures obtained using raw returns. This is consistent with the results shown in Figure 4A using the GPD parameters to estimate VaR and is robust for several probability levels.

Figures $5 \mathrm{~A}$ and $5 \mathrm{~B}$ show the ratios of the $1 \%$ operational VaR to the $1 \%$ catastrophic VaR obtained from the GPD and SGED distributions, respectively. The mean monthly ratio over the entire sample period is 0.52 for the GPD and 0.42 for the SGED distribution, and both ratios are significantly greater than zero and less than one, at the $1 \%$ level. Specifically, the t-statistics from testing the significance of the ratio of $1 \%$ operational VaR to the 1\% catastrophic VaR are 41.92 and 63.59 for GPD and SGED estimates, respectively.

\footnotetext{
${ }^{38}$ As described in footnote 36, we dropped the outlier months of January 2002 and February 2002 from the computation of these average monthly ratios of the operational risk to total equity returns.

${ }^{39}$ Similar results are obtained for $0.5 \%, 1 \%, 1.5 \%, 2 \%$, and $2.5 \%$ catastrophic and operational VaR levels.
} 
The corresponding Newey-West (1987) adjusted t-statistics are 27.84 and 37.71, respectively. Thus, we conclude that operational risk loss levels are lower than overall catastrophic loss levels. Moreover, we examined the tail probabilities for various loss rates (ranging from returns of $-1 \%$ p.a. to $-50 \%$ p.a.) and found that the area under the lower tail of the operational risk distribution was higher than the area under the lower tail of the return distribution for extremely low returns (equity returns below $-12 \%$ ), thereby suggesting that operational risk events are more likely to be the cause of extremely large declines in returns than other risk events. Thus, operational risk events are more likely to be the cause of large unexpected catastrophic losses, although when they occur, the losses are smaller than those resulting from a combination of market risk, credit risk or other risk events.

As an estimate of the dollar magnitude of these losses, we compute average VaR levels for both operational risk and catastrophic risk exposures. On average for all financial institutions over the 1973-2003 sample period, the dollar VaR for catastrophic risk is \$165 million using the GPD methodology and \$156 million using the SGED approach. Operational VaR averaged $\$ 84$ million and $\$ 65$ million, for the GPD and SGED methodologies respectively, over the sample period. Breaking down the dollar VaR calculations by industry, we find that the insurance industry had the largest dollar exposure to both catastrophic and operational risk, on average over the sample period. That is, for insurance companies, the catastrophic dollar VaR averaged \$267 (\$254) million using the GPD (SGED) methodology, and the operational dollar VaR averaged \$132 (\$105) million using the GPD (SGED) methodology. In contrast, depository institutions had average catastrophic dollar VaR of $\$ 184$ (\$174) million using the GPD (SGED) methodology, and average operational dollar VaR of $\$ 93$ (\$72) million using the GPD (SGED) methodology. ${ }^{40}$ Finally, securities firms had the smallest dollar exposure on average over the sample period. Catastrophic dollar VaR averaged $\$ 155$ (\$145) million using the GPD (SGED) methodology, whereas operational dollar VaR averaged \$79 (\$61) million using the GPD (SGED) methodology.

Results using both the GPD and the SGED methodologies suggest that financial intermediaries are exposed to considerable amounts of residual operational risk. Operational risk management presents extremely difficult risk control challenges when compared to the management of other sources of risk exposure, such as market risk, liquidity risk and credit risk. The internal nature of the exposure makes both measurement and management difficult. Young (1999, p.10) states that "open socio-technical systems have an infinite number of ways of failing... The complexity of human behavior prevents errors from being prespecified and reduced to a simple numerical representation." Operational risk is embedded in a firm and cannot be easily separated out. Thus, even if a hedge performs as designed, the firm will be negatively

\footnotetext{
40 de Fontnouvelle, DeJesus-Rueff, Jordan, and Rosengren (2003) use proprietary operational loss databases (OpRisk, OpVantage and the BIS Loss Data Collection Exercise) and estimate the operational risk capital charge to be in the range of \$2-\$7 billion for large financial institutions.
} 
affected in terms of damage to reputation or disruption of business as a result of a low frequency, high severity operational risk event.

\section{Cyclicality in Operational Risk Measures}

In Section VI, we derive a residual measure of operational risk. In this section, we investigate the cyclical components of our operational risk measure. We examine the relationship between the operational risk measures and the cyclical factors presented in Table 1, consisting of monthly data on macroeconomic, cyclical, systemic risk, and regulatory factors. We replicate the univariate analysis used for catastrophic risk, as outlined in Section V. ${ }^{41}$ Tables 4 and 5 present the correlation coefficients for all 43 macroeconomic variables using all seven of the GPD and SGED operational risk parameters, as well as the operational value at risk measures $V a R 1 \%$-ORGPD and VaR1\%-ORSGED.

The results presented in Tables 4 and 5 again display considerable consistency across the GPD and SGED methodologies. Correlation coefficients are similar in size, sign and statistical significance. There is also evidence of procyclicality in the operational value at risk measures, as evidenced by the high level of statististical significance for the correlations between the macroeconomic variables and the VaR measures shown in Table 4 (for GPD estimates) and Table 5 (for SGED estimates). For example, the correlation coefficients on the index of US industrial production and US GDP are positive and statistically significant (at the $1 \%$ level) for both the VaR1\%-ORGPD (0.35 and 0.42 for IndustryIndex and GDP_US, respectively, in Table 4 using the GPD methodology) and for the VaR1\%-ORSGED (0.36 and 0.44, in Table 5 using the SGED methodology). The correlation coefficients on all country stock price indices are positive and statistically significant at the $1 \%$ level, consistent with the results obtained in Tables 2 and 3 for catastrophic risk. All interest rate variables are negatively correlated with operational VaR and all money supply variables are positively correlated with operational VaR (most correlations are statistically significant at the $1 \%$ level). This suggests that operational value at risk declines during the periods of a relatively tight monetary policy consistent with an overheated economy. Similarly, during periods of an easy monetary policy (when interest rates are low and money supply figures are high), generally coincident with economic downturns, the operational value at risk (VaR1\%-ORGPD and $V a R 1 \%$-ORSGED) increases.

The regulatory environment also impacts operational value at risk. As for catastrophic value at risk, the correlation coefficients in Tables 4 and 5 are consistent with significant (at the 1\% level) increases in operational value at risk following the passage of the DIDMCA of 1980, the FDICIA of 1991 and the GLBA of 1999. In addition, operational VaR increased upon passage of the Interstate Banking Act in 1994 and the Basel Accords in 1992 (positive correlation coefficients significant at the $10 \%$ or better).

\footnotetext{
41 We also performed multivariate regression analysis and found evidence consistent with significant cyclicality in the operational risk measures. For example, the adjusted R-squared for the regression model with 13 major macroeconomic variables and $\mathrm{VaR} 1 \%$-GPD ( $\mathrm{VaR} 1 \%-S G E D)$ as the dependent variable is $42.03 \%(48.12 \%)$
} 


\section{Robustness Checks}

\section{A. Cyclicality in Conditional VaR Measures}

The time-series variation in the moments of the empirical return distribution implies that the actual catastrophic risk measures can vary through time. Therefore, we propose a conditional VaR approach to investigate the presence and significance of cyclicality in the conditional catastrophic risk measures. Specifically, we use an MA(1) GARCH-in-mean process with the skewed generalized error distribution (SGED) to model the dynamic behavior of stock returns. The model is as follows:

$$
\begin{gathered}
r_{t}=\alpha_{0}+\alpha_{1} \sigma_{t \mid t-1}+\alpha_{2} \varepsilon_{t-1}+\varepsilon_{t}=\mu_{t \mid t-1}+\varepsilon_{t} \\
E\left(\varepsilon_{t}^{2} \mid \Omega_{t-1}\right)=\sigma_{t \mid t-1}^{2}=\beta_{0}+\beta_{1} \varepsilon_{t-1}^{2}+\beta_{2} \sigma_{t-1}^{2}+\beta_{3} S_{t-1}^{-} \varepsilon_{t-1}^{2} \\
S_{t-1}^{-}=1 \text { if } \varepsilon_{t-1}<0, \text { and } S_{t-1}^{-}=0 \text { otherwise }
\end{gathered}
$$

where $r_{t}$ is the return assumed to follow the SGED density, $\mu_{t \mid t-1}$ is the conditional mean and $\sigma_{t \mid t-1}^{2}$ is the conditional variance of returns based on the information set up to time $t-1, \Omega_{t-1} \cdot \sigma_{t \mid t-1}^{2}$ in equation (23) is originally proposed by Glosten, Jagannathan and Runkle (1993) and known as the GJR-GARCH model. It indicates an asymmetric volatility response to the last period's unexpected news and the last period's variance. ${ }^{42}$ Since $\beta_{3}>0$, negative information shocks will have a greater impact on volatility than positive shocks of the same magnitude. The conditional mean $\mu_{t \mid t-1}$ in equation (22) is a function of the past returns and the current conditional volatility. $\varepsilon_{t}=\sigma_{t} z_{t}$ is the residual process, where $z_{t}=\left(r_{t}-\mu_{t \mid t-1}\right) / \sigma_{t \mid t-1}$ is a series of identically and independently distributed (i.i.d.) standardized returns. Note that because of the i.i.d. assumption, the standardized returns have the same conditional and unconditional probability density function (p.d.f.), i.e., $f\left(z_{t} \mid \Omega_{t-1}\right)=f\left(z_{t}\right)$. On the other hand, the returns $r_{t}$ have a conditional p.d.f. that depends directly on their conditional means and conditional standard deviations. Consequently, computed VaR thresholds for returns also depend on the conditional mean and conditional standard deviation of returns, and as such they are time-varying.

The conditional VaR for $r_{t}$ at a given coverage probability $\alpha$, denoted by $\vartheta_{t \mid t-1}$, is obtained from the solution of the following cumulative distribution of returns,

${ }^{42}$ Following the introduction of ARCH models by Engle (1982) and their generalization (GARCH) by Bollerslev (1986), there have been numerous refinements of this approach to estimating conditional volatility. Most of the refinements have been driven by empirical regularities in financial data. Asymmetry (or asymmetric volatility response to past information shocks) seems to be responsible for the plethora of extant GARCH models. Following Black's (1976) exploration of this phenomenon, it is now commonly referred to as the leverage effect: changes in stock prices tend to be negatively related to changes in volatility. The GJR-GARCH model of Glosten, Jagannathan, and Runkle (1993) is one of the most popular asymmetric GARCH models used in the existing literature. 


$$
\operatorname{Pr}\left(r_{t} \leq \vartheta_{t \mid t-1} \mid \Omega_{t-1}\right)=\int_{-\infty}^{\vartheta_{t \mid t-1}} f\left(r_{t} \mid \Omega_{t-1}\right) d r_{t}=\alpha,
$$

where $f\left(r_{t} \mid \Omega_{t-1}\right)$ is the conditional p.d.f. for returns. Note that the above probability function can be written in terms of the standardized returns in the following equivalent form:

$$
\begin{aligned}
\operatorname{Pr}\left(r_{t} \leq \vartheta_{t \mid t-1} \mid \Omega_{t-1}\right)= & \operatorname{Pr}\left(\frac{r_{t}-\mu_{t \mid t-1}}{\sigma_{t \mid t-1}} \leq \frac{\vartheta_{t \mid t-1}-\mu_{t \mid t-1}}{\sigma_{t \mid t-1}} \mid \Omega_{t-1}\right) \\
& \operatorname{Pr}\left(z_{t} \leq a=\frac{\vartheta_{t \mid t-1}-\mu_{t \mid t-1}}{\sigma_{t \mid t-1}}\right)=\int_{-\infty}^{a} f\left(z_{t}\right) d z_{t}=\alpha,
\end{aligned}
$$

where the p.d.f. for the standardized returns $f\left(z_{t}\right)$ and the threshold $a$ associated with the coverage probability $\alpha$ do not depend on time or the information set $\Omega_{t-1}$. The latter is a byproduct of the assumption that the series of standardized returns is i.i.d. Given the estimated threshold $a$ for the standardized returns, the conditional (time-varying) VaR for the returns can be computed using the transformation

$$
\vartheta_{t \mid t-1}=\mu_{t \mid t-1}+a \sigma_{t \mid t-1},
$$

where the conditional mean, $\mu_{t \mid t-1}$, and the conditional volatility of returns, $\sigma_{t \mid t-1}$, are computed using equations (22) and (23).

We test cyclicality in the conditional catastrophic risk measures of major financial institutions. ${ }^{43}$ First, we generate the value-weighted portfolio returns for major, recognizable financial institutions, and for each of the three industry sectors (depository institutions, insurance companies, and securities firms). ${ }^{44}$ Second, we use the value-weighted portfolio returns to estimate the MA(1) SGED-GJRGARCH-in-mean model given in equations (22)-(23) for the entire financial industry and for each of the three sub-groups. Finally, based on the maximum likelihood parameter estimates we compute the conditional $1 \%$ VaR using equation (26).

Figure 6A plots the conditional catastrophic risk measures from January 1973 to December $2003 .{ }^{45}$ A notable point in Figure $6 \mathrm{~A}$ is that the conditional 1\% VaR of depository institutions is higher than the $1 \%$ $\mathrm{VaR}$ of insurance companies and securities firms, as in our results for unconditional catastrophic VaR. However, the insurance companies have higher VaR levels than the depository institutions during a few months, most notably shown as huge spikes in VaR for insurance companies during the last quarter of 1974 and the second quarter of 2000. Over the sample period of 1973-2003, the unconditional mean of the

\footnotetext{
43 Appendix A lists major financial institutions used in our analysis of the conditional value at risk.

44 The industry segment groupings were done by SIC code, such that depository institutions included SIC codes 60XX, 66XX and 6712; insurance companies included SIC codes 63XX and 64XX; and securities firms included all other 6XXX-level SIC codes.

45 Since we do not use the COMPUSTAT data when calculating conditional VaR measures, we do not lose any observations and thus the results are based on the entire sample period of January 1973 to December 2003.
} 
conditional $1 \%$ VaR measures is equal to $14.70 \%$ for the whole industry, $18.39 \%$ for depository institutions, $15.01 \%$ for securities firms, and $14.31 \%$ for insurance companies. The sample standard deviation of the conditional $1 \% \mathrm{VaR}$ measures is equal to $1.99 \%$ for the whole industry, $1.87 \%$ for depository institutions, $2.12 \%$ for securities firms, and $3.71 \%$ for insurance companies.

To check the presence and significance of cyclicality in the conditional catastrophic risk measures, we calculate the correlation coefficients between the conditional 1\% VaR measures and the 43 macroeconomic variables. Based on the $p$-values, there are 22 (out of 43) correlations that are statistically significant at least at the $10 \%$ level or better for the entire industry. Better results are obtained for the three sub-groups. Specifically, we have 30, 28, and 27 statistically significant correlation coefficients for the depository institutions, securities firms, and insurance company subsamples, respectively. ${ }^{46}$

In addition to the conditional catastrophic risk measures, we investigate the cyclicality in the conditional operational risk measures. Using a similar version of equation (21), we generate the time-series of residuals for major, recognizable institutions and for each of the three industry sectors. More specifically, we regress the value-weighted portfolio returns on the first differences of macroeconomic risk variables, three Fama-French (1993) factors, and the momentum factor in order to generate the time-series of residuals for the whole industry and three sub-groups. Then, we use the residual series to estimate the MA(1) SGEDGJRGARCH-in-mean model given in equations (22)-(23) for the entire financial industry and for each of the three sub-groups. Finally, based on the maximum likelihood parameter estimates we compute the conditional operational $1 \%$ VaR.

Figure 6B plots the conditional operational VaR measures from January 1973 to December 2003. Similar to the conditional catastrophic VaR measures depicted in Figure 6A, the conditional operational 1\% $\mathrm{VaR}$ of depository institutions is generally higher than the $1 \%$ operational VaR of insurance companies and securities firms. However, the insurance companies have higher operational VaR levels than the depository institutions during the late 1970s and early 1980s, most notably shown as huge spikes in VaR for insurance companies during the period of 1977-1979 and 2000-2001. Over the period of 1973-2003, the sample mean of the conditional operational $1 \% \mathrm{VaR}$ measures is equal to $4.54 \%$ for the whole industry, $7.61 \%$ for depository institutions, $3.23 \%$ for securities firms, and $7.37 \%$ for insurance companies. The standard deviation of the $1 \%$ operational $\mathrm{VaR}$ measures is equal to $1.62 \%$ for the whole industry, $0.68 \%$ for depository institutions, $0.89 \%$ for securities firms, and $2.04 \%$ for insurance companies.

We calculate the ratio of the conditional operational $1 \% \mathrm{VaR}$ to the conditional catastrophic $1 \% \mathrm{VaR}$ measures for the whole industry and three sub-groups. Similar to our findings from the unconditional VaR measures, the average ratio over the sample period of 1973-2003 is about 0.31 for the whole industry, 0.40 for depository institutions, 0.21 for securities firms, and 0.55 for insurance companies. 
To test for the presence and significance of cyclicality in the conditional operational VaR measures, we compute the correlations between the conditional operational $1 \%$ VaR measures and the 43 macroeconomic variables. Based on the $p$-values, there are 38 (out of 43) correlations that are statistically significant at least at the $10 \%$ level or better for the entire industry. The results are almost the same for the three sub-groups. Specifically, we have 27, 33, and 41 statistically significant correlation coefficients for the depository institutions, securities firms, and insurance companies, respectively. ${ }^{47}$

Overall, the results provide strong evidence that our main findings on cyclicality are robust across unconditional and conditional measures of catastrophic and operational risk.

\section{B. Alternative Distribution Functions}

As discussed earlier, there is substantial empirical evidence that the distribution of stock returns is skewed, fat tailed and shows high peaks. To account for skewness and kurtosis in the data, earlier studies used symmetric fat-tailed or skewed fat-tailed distributions to model the unconditional or conditional distribution of financial returns. One distribution that is used extensively and can accommodate thick tails is the Student $t$ distribution. Two other distributions that have been used for leptokurtic data are the generalized error distribution (GED), which is also referred to as the power exponential distribution, and the generalized $t$ (GT) distribution. The GED was originally introduced by Subbotin (1923) and then used by Box and Tiao (1962), Nelson (1991), and Hsieh (1989) among others. The GED includes the Normal and the Laplace as special cases. McDonald and Newey (1988) introduced the generalized t (GT) distribution, which is symmetric about its mean and generalizes both the Student $t$ and GED distributions.

Although the Student t, GED, and GT distributions allow for considerable flexibility for the values of kurtosis, they cannot model skewness which is observed in many economic time series. Five flexible parameter distributions which can model both skewed and thick-tailed empirical distributions are the skewed t distribution of Hansen (1994), the skewed generalized error distribution (SGED) of Bali and Theodossiou (2003), the skewed generalized $\mathrm{t}$ (SGT) distribution of Theodossiou (1998), the exponential generalized beta of the second kind (EGB2) distribution of McDonald and Xu (1995), and the inverse hyberbolic sine (IHS) distribution of Johnson (1949). ${ }^{48}$

Bali and Theodossiou (2004) test the empirical performance of the aforementioned distributions and find that the skewed generalized $\mathrm{t}$ (SGT) and the skewed generalized error distribution (SGED) provide a very accurate characterization of stock market returns. They indicate that the SGT and SGED distributions

\footnotetext{
${ }^{46}$ To save space, we do not report the correlation coefficients between the conditional catastrophic VaR measures and the macroeconomic variables. They are available upon request.

${ }^{47}$ To save space, we do not report the correlation coefficients between the conditional operational VaR measures and the macroeconomic variables. They are available upon request.

48 The interested reader may wish to consult Bali and Theodossiou (2004) for a detailed description of alternative distribution functions.
} 
model the tails of the empirical distribution better than the Student t, GED, GT, skewed t, EGB2, IHS, Laplace, and Normal distributions. ${ }^{49}$ Following Bali and Theodossiou (2004), we use the skewed generalized error distribution (SGED) to estimate the catastrophic and operational risk measures. However, to check the robustness of our findings, we also use the skewed generalized $t$ distribution, which nests many well known symmetric and asymmetric fat-tailed distributions.

The skewed generalized $\mathrm{t}(\mathrm{SGT})$ probability density function is:

$$
S G T(r ; \mu, \sigma, n, k, \lambda)=\frac{C}{\sigma}\left(1+\frac{|\varepsilon|^{k}}{((n-2) / k)(1+\operatorname{sign}(\varepsilon) \lambda)^{k} \theta^{k} \sigma^{k}}\right)^{-(n+1) / k}
$$

where $C=k /\left(2((n-2) / k)^{1 / k} \theta B(1 / k, n / k)\right), \quad \theta=(k /(n-2))^{1 / k} B(1 / k, n / k)^{0.5} B(3 / k,(n-2) / k)^{-0.5} S(\lambda)^{-1}$, $S(\lambda)=\sqrt{1+3 \lambda^{2}-4 A^{2} \lambda^{2}}, \quad A=B(2 / k,(n-1) / k) B(1 / k, n / k)^{-0.5} B(3 / k,(n-2) / k)^{-0.5}, \quad \delta=2 \lambda A S(\lambda)^{-1}, \mu$ and $\sigma$ are the mean and standard deviation of $r ; n$ and $k$ are kurtosis parameters; $\lambda$ is a skewness parameter obeying the constraint $|\lambda|<1$, sign is the sign function, $B(\cdot)$ is the beta function and $\varepsilon=r-\mu+\delta \sigma$. In the above density, $\mu-\delta \sigma$ is the mode and $\delta=(\mu-\operatorname{mode}(y)) / \sigma$ is Pearson's skewness.

The SGT nests several well-known distributions. Specifically, it gives for $\lambda=0$ the generalized-t of McDonald and Newey (1988); for $k=2$ the skewed t of Hansen (1994); for $n=\infty$ the skewed generalized error distribution of Bali and Theodossiou (2003); for $n=\infty$ and $\lambda=0$ the generalized error distribution or power exponential distribution of Subbotin (1923); for $k=2$ and $\lambda=0$ the Student $\mathrm{t}$ distribution; for $n=\infty, \lambda$ $=0$ and $k=1$ the Laplace or double exponential distribution; for $n=\infty, \lambda=0$ and $k=2$ the Normal distribution; and for $n=\infty, \lambda=0$ and $k=\infty$ the Uniform distribution.

As shown in Figure 7, the time-series pattern of the 1\% catastrophic and operational VaR measures obtained from the GPD, SGED, and SGT distributions are all very similar over the sample period of April 1973-June 2003. The only difference is that the catastrophic and operational VaR measures of SGT are smaller than those of the GPD and SGED. However, we calculate the ratio of $1 \%$ operational VaR to the $1 \%$ catastrophic VaR obtained for the SGT and the mean monthly ratio is found to be 0.61 , which is close to those obtained from the GPD and SGED distributions.

We also check the presence and significance of cyclicality in the catastrophic and operational risk measures of SGT by calculating the correlations between the $1 \% \mathrm{VaR}$ measures and 43 macroeconomic variables. Table 6 shows that for the catastrophic VaR estimates there are 29 (out of 43) correlations that are statistically significant at least at the $10 \%$ level, and 22 of them are significant at least at the $1 \%$ level. Similar to our findings from the GPD and SGED, for the operational VaR estimates, we have 38 (out of 43) correlations that are statistically significant at least at the $10 \%$ level, with 30 correlations significant at the

49 Their results are robust across different stock market indices. They use daily returns on the S\&P 500 (1/4/196512/31/2002), NYSE (1/3/1966-12/31/2002), NASDAQ (2/5/1971-12/31/2002), and DJIA (5/26/1896-12/31/2002). 
$1 \%$ level. Most importantly, the size and sign of the correlation coefficients in Table 6 are quite similar to those obtained using the GPD and SGED, presented in Tables 2 and 3 for catastrophic risk and Tables 4 and 5 for operational risk. These results indicate that our main findings on cyclicality are robust across alternative distribution functions.

\section{Monte Carlo Simulation}

To further check the robustness of cyclicality in catastrophic and operational risk measures, we investigate the implied behavior of the VaR estimates via Monte Carlo simulation. In order to generate the simulated returns series, we assume that the (log)-stock price movements are described by the following stochastic differential equation,

$$
d \ln P_{t}=\mu d t+\sigma d W_{t}
$$

where $P_{t}$ is the price level at time $t, W_{t}$ is a standard Wiener process with zero mean and variance of $d t, \mu$ and $\sigma$ are the drift and diffusion parameters. In discrete time, equation (28) yields a return process:

$$
\ln P_{t+\Delta}-\ln P_{t} \equiv r_{t}=\mu \Delta t+\sigma z \sqrt{\Delta t}
$$

where $r_{t}$ is the return at time $t, \Delta t$ is the length of time interval in which the discrete time data are generated, and $\Delta W_{t}=z \sqrt{\Delta t}$ is the Wiener process with zero mean and variance of $\Delta t$. In our simulation analysis, $\mu$ and $\sigma$ are the annualized mean and standard deviation of returns and the stochastic process is discretized into monthly intervals with $\Delta t=1 / 12$.

Before performing the simulations based on equation (29), we first generate the value-weighted portfolio returns of all financial institutions from January 1973 to December 2003. Second, we calculate the sample mean and standard deviation of the time-series portfolio returns and use them as estimators of $\mu$ and $\sigma$ in equation (29). Finally, to be consistent with our actual sample (January 1973-December 2003) which has 372 monthly returns, we draw 372 random variables (denoted by $z$ ) from a normal distribution $N(\mu, \sigma)$ to generate one simulated return series. This procedure is repeated 10,000 times for the entire sample period.

After we generate 10,000 simulated returns for each month from January 1973 to December 2003, we use the skewed generalized error distribution to estimate the $1 \%$ catastrophic and operational VaR measures and check the presence and significance of cyclicality. We compute the correlations between the $1 \% \mathrm{VaR}$ measures and 43 macroeconomic variables. Similar to our earlier findings from the GPD, SGED, and SGT distributions with actual data, for the catastrophic VaR estimates there are 22 (out of 43) correlations that are statistically significant at the $10 \%$ level or better, and 12 of them are significant at the $1 \%$ level. For the operational VaR estimates, we have 32 (out of 43) correlations that are statistically 
significant at the $10 \%$ level or better, with 15 correlations significant at the $1 \%$ level. ${ }^{50}$ The results indicate that our main findings on cyclicality hold for the simulated return series as well as the empirical dataset.

\section{Conclusion}

We examine the catastrophic risk of financial institutions and test for procyclicality. We utilize an extreme value approach (Generalized Pareto Distribution, GPD), as well as a generalized distributional approach (Skewed Generalized Error Distribution, SGED) to obtain estimates of catastrophic risk parameters and $1 \%$ value at risk (VaR). We find evidence of procyclicality in the catastrophic VaR for financial institutions.

We define a new, residual operational risk measure and estimate the risk parameters using both the GPD and SGED. We use these operational risk parameters to determine the $1 \%$ operational VaR. Using our measure, we find that operational risk is quite significant, comprising approximately $18 \%$ of the total equity returns of financial institutions. This paper presents the first evidence of procyclicality in operational risk measures.

Results are consistent across methodologies for both catastrophic and operational risk measures. Our results are robust to alternative distributional specifications, conditionality in the VaR, and simulated databases. Thus, we conclude that macroeconomic, systematic and environmental factors play a considerable role in influencing the risk of financial institutions. Models that ignore these factors are therefore fundamentally flawed. These results provide encouragement for further research into both catastrophic and operational risk measures that are conditioned on cyclical factors.

\footnotetext{
50 To save space, we do not report the correlation coefficients between the VaR measures obtained from simulated returns and the macroeconomic variables. They are available upon request.
} 


\section{References}

Allen, L., J. Boudoukh and A. Saunders, 2004. Understanding Market, Credit and Operational Risk: The Value at Risk Approach, Blackwell Publishing, Oxford.

Allen, L. and A. Saunders, 1992. "Bank Window Dressing: Theory and Evidence," Journal of Banking and Finance 16, 585-623.

Allen, L. and A. Saunders, 2002, "Cyclical Effects in Credit Risk Ratings and Default Risk," in Credit Ratings: Methodologies, Rationale and Default Risk, Michael Ong, ed., London: Risk Books, 2002, pp. 45-79.

Allen, L. and A. Saunders, 2004, "Incorporating Systemic Influences into Risk Measures: A Survey of the Literature," Journal of Financial Services Research, forthcoming.

Bali, T. G., 2003. "An Extreme Value Approach to Estimating Volatility and Value at Risk." Journal of Business 76, 83-108.

Bali, T. G., N. Cakici, X. Yan, and Z. Zhang, 2003. “Does Idiosyncratic Risk Really Matter?” Journal of Finance forthcoming.

Bali, T. G., and S. Neftci, 2003. "Disturbing Extremal Behavior of Spot Rate Dynamics." Journal of Empirical Finance 10, 455-477.

Bali, T. G., and P. Theodossiou, 2003. "A Conditional-SGT-VaR Approach with Alternative GARCH Models." Annals of Operations Research forthcoming.

Bali, T. G., and P. Theodossiou, 2004. "Risk Measurement Performance of Alternative Distribution Functions." Working Paper, Baruch College, City University of New York.

Bank for International Settlements, "Working Paper on the Regulatory Treatment of Operational Risk," September 2001.

Basak, S. and A. Shapiro, 2001, "Value-at-Risk-Based Risk Management: Optimal Policies and Asset Prices," Review of Financial Studies 14, 371-405.

Black, F., 1976. "Studies in Stock Price Volatility Changes." Proceedings of the 1976 Business Meeting of the Business and Economic Statistics Section, American Statistical Association, 177-181.

Bollerslev, T., 1986. “Generalized Autoregressive Conditional Heteroscedasticity.” Journal of Econometrics 31, 307-327.

Box, G.E.P. and G.C. Tiao, 1962.“A Further Look at Robustness via Bayes’s Theorem.”Biometrica 49,419-432.

Campbell, J. Y., M. Lettau, B. G. Malkiel, and Y. Xu, 2001. "Have Individual Stocks Become More Volatile? An Empirical Exploration of Idiosyncratic Risk.” Journal of Finance 56, 1-43.

Chernobai, A., and S. Rachev, 2004. "Stable Modelling of Operational Risk," in Operational Risk Modelling and Analysis: Theory and Practice, M. Cruz, editor, Risk Books, London, pp. 139-170.

Currie, C.V., 2004, "Basel II and Operational Risk - An Overview," in Operational Risk Modelling and Analysis: Theory and Practice, M. Cruz, editor, Risk Books, London, pp. 59-104. 
de Fontnouvelle, P., V. DeJesus-Rueff, J. Jordan, and E. Rosengren, 2003. "Capital and Risk: New Evidence on Implications of Large Operational Losses,” Working Paper, Federal Reserve Bank of Boston.

Ebnother, S., P. Vanini, A. McNeil, and P. Antolinez, 2003. “Operational Risk: A Practitioner's View,” Journal of Risk 5, 1-15.

Embrechts, P., C. Kluppelberg, and T. Mikosch, 1997. Modeling Extremal Events, Springer: Berlin Heidelberg.

Engle, R. F., 1982. "Autoregressive Conditional Heteroscedasticity with Estimates of the Variance of United Kingdom Inflation.” Econometrica 50, 987-1007.

Fama, E. F., and K. French, 1993. "Common risk factors in the returns on stocks and bonds." Journal of Financial Economics 33, 3-56.

Glosten, L. R., R. Jagannathan, and D. E. Runkle, 1993. "On the Relation Between the Expected Value and the Volatility of the Nominal Excess Return on Stocks.” Journal of Finance 48, 1779-1801.

Goyal, A., and P. Santa-Clara, 2003. "Idiosyncratic Risk Matters!” Journal of Finance 58, 975-1008.

Haas, M. and T. Kaiser, 2004 "Tackling the Insufficiency of Loss Data for the Quantification of Operational Risk," in Operational Risk Modelling and Analysis: Theory and Practice, M. Cruz, editor, Risk Books, London, pp. 13-24.

Hansen, B. E. 1994, “Autoregressive Conditional Density Estimation,” International Economic Review, 35, 705 730.

Hsieh, D., 1989. "Modeling Heteroskedasticity in Daily Foreign Exchange Rates." Journal of Business and Economic Statistics 7, 307-317.

Johnson, N. L. 1949. "Systems of Frequency Curves Generated by Methods of Translation," Biometrica 36, 149-176.

Kingsley, S., A. Rolland, A. Tinney and P. Holmes, 1998. "Operational Risk and Financial Institutions: Getting Started,” in Operational Risk and Financial Institutions, Arthur Andersen Risk Books, pp. 3-28.

Kalhoff, A. and M. Haas, 2004, "Operational Risk - Management Based on the Current Loss Data Situation," in Operational Risk Modelling and Analysis: Theory and Practice, M. Cruz, editor, Risk Books, London, pp. 5-12.

Kashyap, A.K. and J.C. Stein, 2004, “Cyclical Implications of the Basel II Capital Standards,” Economic Perspectives, Federal Reserve Bank of Chicago, First Quarter, pp. 18-31.

Kodres, L., and M. Pritsker, 2002. “A Rational Expectation Model of Financial Contagion," Journal of Finance 57, 769-799.

Kuritzkes, A., 2002. “Operational Risk Capital: A Problem of Definition,” Journal of Risk Finance Fall, 1-10.

Kyle, A., and W. Xiong, 2001, “Contagion as a Wealth Effect,” Journal of Finance 56, 1401-1440.

Leadbetter, M. R., G., Lindgren, and H. Rootzen, 1983. Extremes and Related Properties of Random Sequences and Processes, Springer-Verlag: New York.

Longin, F. M., 1996. "The Asymptotic Distribution of Extreme Stock Market Returns.” Journal of Business 69, 383-408. 
Longin, F. M., 2000. "From Value at Risk to Stress Testing: The Extreme Value Approach.” Journal of Banking and Finance 24, 1097-1130.

Longin, F. M., and B. Solnik, 2001. "Extreme Correlation of International Equity Markets," Journal of Finance $56,649-676$.

Lowe, P., 2002. “Credit Risk Measurement and Procyclicality,” BIS Working Papers, No. 116, September 2002.

McDonald, J. B. and W. K. Newey 1988. "Partially Adaptive Estimation of Regression Models Via the Generalized t Distribution," Econometric Theory, 4, 428-457.

McDonald, J. B. and Y. J. Xu, 1995. "A Generalization of the Beta Distribution with Applications," Journal of Econometrics, 66, 133-152.

McNeil, A. J., and R. Frey, 2000. "Estimation of Tail-Related Risk Measures for Heteroscedastic Financial Time Series: An Extreme Value Approach.” Journal of Empirical Finance 7, 271-300.

Merton, R.C., 1987, “A Simple Model of Capital Market Equilibrium with Incomplete Information,” Journal of Finance 42, 483-510.

Nelson, D. B., 1991. "Conditional Heteroscedasticity in Asset Returns: A New Approach,” Econometrica 59, 347-370.

Newey, W. K., and K. D. West, 1987, A Simple, Positive Semi-definite, Heteroskedasticity and Autocorrelation Consistent Covariance Matrix, Econometrica 55, 703-708.

Pickands, J., 1975. "Statistical Inference Using Extreme Order Statistics.” Annals of Statistics 3, 119-131.

Resnick, S. I., 1987. Extreme Values, Regular Variation, and Point Processes, Springer-Verlag: NY.

Rigobon, R., and K. Forbes, 2002. "No Contagion, Only Interdependence: Measuring Stock Market Comovements," Journal of Finance 57, 2223-2261.

Shapiro, A., 2002, "The Investor Recognition Hypothesis in a Dynamic General Equilibrium: Theory and Evidence," Review of Financial Studies 15, 97-141.

Subbotin, M.T., 1923. “On the Law of Frequency Error.” Matematicheskii Sbornik 31, 296-301.

Theodossiou, P., 1998. "Financial Data and the Skewed Generalized t Distribution." Management Science 44, $1650-61$.

Young, B., 1999. "Raising the Standard,” Operational Risk Special Report, Risk, November, 10-12. 


\section{Appendix A: Major Recognizable Financial Institutions}

These firms were chosen by size (market capitalization) and data availability of equity returns in CRSP. The industry segment groupings were done by SIC code, such that depository institutions included SIC codes 60XX, 66XX and 6712; insurance companies included SIC codes 63XX and 64XX; and securities firms included all other 6XXX-level SIC codes.

\begin{tabular}{|c|c|c|}
\hline Depository Institutions & Insurance Companies & Securities Firms \\
\hline CITIGROUP INC & AMERICAN INTERNATIONAL GROUP INC & FEDERAL NATIONAL MORTGAGE ASSN \\
\hline BANK OF AMERICA CORP & BERKSHIRE HATHAWAY INC DEL & MORGAN STANLEY DEAN WITTER \& CO \\
\hline WELLS FARGO \& CO NEW & ALLSTATE CORP & AMERICAN EXPRESS CO \\
\hline J P MORGAN CHASE \& CO & METLIFE INC & MERRILL LYNCH \& CO INC \\
\hline WACHOVIA CORP & MARSH \& MCLENNAN COS INC & GOLDMAN SACHS GROUP INC \\
\hline U S BANCORP DEL & AMBAC FINANCIAL GROUP INC & PRUDENTIAL FINANCIAL INC \\
\hline BANK ONE CORP & AFLACINC & LEHMAN BROTHERS HOLDINGS INC \\
\hline DEUTSCHE BANK AG & PROGRESSIVE CORP OH & SCHWAB CHARLES CORP NEW \\
\hline FLEETBOSTON FINANCIAL CORP & HARTFORD FINANCIAL SVCS GROUP IN & FRANKLIN RESOURCES INC \\
\hline WASHINGTON MUTUAL INC & SUN LIFE FINANCIAL INC & EQUITY OFFICE PROPERTIES TRUST \\
\hline M B N A CORP & MANULIFE FINANCIAL CORP & BURLINGTON RESOURCES INC \\
\hline ROYAL BANK CANADA MONTREAL QUE & WELLPOINT HEALTH NETWORKS INC & SIMON PROPERTY GROUP INC NEW \\
\hline BANK OF NOVA SCOTIA & CHUBB CORP & EQUITY RESIDENTIAL PROP TRUST \\
\hline BANK NEW YORK INC & ACE LTD & BEAR STEARNS COS INC \\
\hline TORONTO DOMINION BANK ONT & HANCOCK JOHN FINANCIAL SVCS INC & VORNADO REALTY TRUST \\
\hline B B \& T CORP & PRINCIPAL FINANCIAL GROUP INC & AMERITRADE HOLDING CORP \\
\hline BANK MONTREAL QUE & X L CAPITAL LTD & T ROWE PRICE GROUP INC \\
\hline NATIONAL CITY CORP & ANTHEM INC & \\
\hline CANADIAN IMPERIAL BNK OF COMMERC & AETNA INC NEW & \\
\hline STATE STREET CORP & LOEWS CORP & \\
\hline P N C FINANCIAL SERVICES GRP INC & ST PAUL COS INC & \\
\hline KEYCORP NEW & M B I A INC & \\
\hline M \& T BANK CORP & TRAVELERS PROPERTY CASUALTY CORP & \\
\hline SOUTHTRUST CORP & C I G N A CORP & \\
\hline NORTHERN TRUST CORP & AON CORP & \\
\hline \multicolumn{3}{|l|}{ COMERICA INC } \\
\hline SUNTRUST BANKS INC & & \\
\hline
\end{tabular}




\section{Table 1}

Panel A. Sources of Data on Cyclical Factors

\begin{tabular}{|c|c|c|c|c|}
\hline $\begin{array}{c}\text { Variable } \\
\text { Name }\end{array}$ & $\begin{array}{c}\text { Variable } \\
\text { Description }\end{array}$ & Data Source & $\begin{array}{l}\text { Number } \\
\text { of Obs. }\end{array}$ & Data Range \\
\hline Consentiment & $\begin{array}{l}\text { Consumer Sentiment } \\
\text { University of Mich }\end{array}$ & Economagic & 372 & $1973-2003$ \\
\hline USunempl & $\begin{array}{c}\text { US Unemployment } \\
\text { Rate } \\
\end{array}$ & Bureau of Labor Statistics & 372 & $1973-2003$ \\
\hline RsvAst & $\begin{array}{l}\text { Aggregate Bank } \\
\text { Reserve to Assets }\end{array}$ & $\begin{array}{c}\text { Federal Reserve Bank } \\
\text { Kansas City } \\
\end{array}$ & 264 & $1980-2001$ \\
\hline BusBnkrpcy & $\begin{array}{c}\text { No. of US Business } \\
\text { Bankruptcies }\end{array}$ & $\begin{array}{c}\text { Administrative Office of } \\
\text { Courts }\end{array}$ & 276 & $1980-2003$ \\
\hline GDP_US & US GDP & $\begin{array}{c}\text { Bureau Economic } \\
\text { Analysis } \\
\end{array}$ & 372 & $1973-2003$ \\
\hline IndstryIndex & $\begin{array}{l}\text { US Industrial } \\
\text { Production }\end{array}$ & Global Insight (DRI) & 372 & $1973-2003$ \\
\hline exgeus & Dmark/US\$ FX Rate & WRDS FX File & 312 & 1973-1998 \\
\hline exukus & UK/US\$ FX Rate & WRDS FX File & 372 & $1973-2003$ \\
\hline Exjpus & JP/US\$ FX Rate & WRDS FX File & 372 & $1973-2003$ \\
\hline FPS6CA & Equity Index Canada & DRI & 372 & $1973-2003$ \\
\hline FPS6FR & Equity Index France & DRI & 372 & $1973-2003$ \\
\hline FPS6IT & Equity Index Italy & DRI & 372 & $1973-2003$ \\
\hline FPS6JP & Equity Index Japan & DRI & 372 & $1973-2003$ \\
\hline FPS6UK & Equity Index UK & DRI & 372 & $1973-2003$ \\
\hline FPS6WG & Equity Ind.Germany & DRI & 372 & $1973-2003$ \\
\hline SPINDX & S\&P 500 Index & CRSP Indices & 372 & $1973-2003$ \\
\hline CPI_JP & CPI Japan & Statistic Bureau of Japan & 372 & $1973-2003$ \\
\hline CPI_UK & CPI UK & National Statistics of UK & 372 & $1973-2003$ \\
\hline CPI_US & CPI US & Bureau of Labor Statistics & 372 & $1973-2003$ \\
\hline CPI_G & CPI Germany & Eurostat & 336 & $1973-2000$ \\
\hline R_3MTB & 3 month US T-bills & $\begin{array}{c}\text { Federal Reserve Bank of } \\
\text { St. Louis - FRED } \\
\end{array}$ & 372 & $1973-2003$ \\
\hline R_10YTB & $10 \mathrm{yr}$ US T-bonds & FRED & 372 & $1973-2003$ \\
\hline R_AAA & AAA bond rate & FRED & 372 & $1973-2003$ \\
\hline R_Baa & Baa bond rate & FRED & 372 & $1973-2003$ \\
\hline RMIB3S_a_UZ & 3 mo.Euribor rate & DRI & 372 & $1973-2003$ \\
\hline RMGB10Y_a_GY & 10 yr German T-bond & DRI & 372 & $1973-2003$ \\
\hline RMBANK_a_JP & Discount rate Japan & DRI & 372 & $1973-2003$ \\
\hline RMGBL_a_JP & Long Japanese bond & DRI & 372 & $1973-2003$ \\
\hline RMGBS_a_UK & 91 day UK T-bill & DRI & 372 & $1973-2003$ \\
\hline RMGBL_a_UK & $10 \mathrm{yr}$ UK T-bond & DRI & 372 & $1973-2003$ \\
\hline
\end{tabular}




\begin{tabular}{|c|c|c|c|c|}
\hline $\begin{array}{c}\text { Variable } \\
\text { Name } \\
\end{array}$ & $\begin{array}{c}\text { Variable } \\
\text { Description }\end{array}$ & Data Source & $\begin{array}{l}\text { Number } \\
\text { of Obs. }\end{array}$ & Data Range \\
\hline M2SL & US M2 money supply & FRED & 372 & $1973-2003$ \\
\hline M2_a_JP & JP M2 money supply & DRI & 372 & $1973-2003$ \\
\hline M2NS_a_GY & German M2 money & DRI & 288 & $1980-2003$ \\
\hline M2_a_UK & UK M2 money & DRI & 258 & $1982-2003$ \\
\hline M2_a_UZ & EU M2 Money & DRI & 282 & $1980-2003$ \\
\hline JM2_a_UZ & M2 Index Eurozone & DRI & 282 & $1980-2003$ \\
\hline DUM_DIDMCA & $\begin{array}{l}\text { Depository Institution } \\
\text { Deregulatory and } \\
\text { Monetary Control Act } \\
\text { dummy variable }\end{array}$ & constructed & 372 & $1973-2003$ \\
\hline DUM_FDICIA & $\begin{array}{l}\text { FDIC Improvement } \\
\text { Act dummy variable }\end{array}$ & constructed & 372 & $1973-2003$ \\
\hline DUM_Basel & $\begin{array}{l}\text { Implementation of } \\
\text { Basel I dummy var. }\end{array}$ & constructed & 372 & $1973-2003$ \\
\hline DUM_Interstate & $\begin{array}{c}\text { Riegle-Neal Interstate } \\
\text { Banking \& Branching } \\
\text { Efficiency Act var. }\end{array}$ & constructed & 372 & $1973-2003$ \\
\hline DUM_GLBA & $\begin{array}{l}\text { Gramm-Leach-Bliley } \\
\text { Act dummy var. }\end{array}$ & constructed & 372 & $1973-2003$ \\
\hline DUM_NBER & $\begin{array}{l}\text { Recessions as marked } \\
\text { by NBER dummy var }\end{array}$ & NBER website & 372 & $1973-2003$ \\
\hline RegDum & $\begin{array}{l}=1 \text { for the first month } \\
\text { of each of the } 5 \text { reg. } \\
\text { changes above: } \\
\text { DIDMCA, FDICIA, } \\
\text { Basel, Interstate, and } \\
\text { GLBA; } 0 \text { otherwise }\end{array}$ & constructed & 372 & $1973-2003$ \\
\hline
\end{tabular}


Panel B. Descriptive Statistics for Cyclical Factors

\begin{tabular}{|c|c|c|c|c|c|c|}
\hline Variable Name & $\begin{array}{c}\text { Variable } \\
\text { Description }\end{array}$ & Mean & Std. Dev. & Median & Minimum & Maximum \\
\hline Consentiment & $\begin{array}{c}\text { Consumer Sentiment } \\
\text { University of Michigan } \\
\end{array}$ & 86.10 & 12.93 & 89.3 & 51.7 & 112 \\
\hline USunempl & US Unemployment Rate & $6.34 \%$ & $1.44 \%$ & $6.0 \%$ & $3.8 \%$ & $10.8 \%$ \\
\hline RsvAst & $\begin{array}{c}\text { Aggregate Bank Reserve } \\
\text { to Assets }\end{array}$ & $1.12 \%$ & $0.37 \%$ & $1.08 \%$ & $0.54 \%$ & $1.64 \%$ \\
\hline BusBnkrpcy & $\begin{array}{c}\text { Number of US Business } \\
\text { Bankruptcies }\end{array}$ & 4760 & 1228 & 4787 & 2577 & 9534 \\
\hline GDP_US & US GDP & $\$ 1,691.94 \mathrm{~b}$ & $\$ 879.66 \mathrm{~b}$ & $\$ 1,577.67 \mathrm{~b}$ & $\$ 446.13 \mathrm{~b}$ & $\$ 3,384.31 \mathrm{~b}$ \\
\hline IndstryIndex & US Industrial Production & 78.25 & 19.64 & 74.85 & 48.89 & 118.77 \\
\hline exgeus & Dmark/US\$ FX Rate & $\begin{array}{c}\mathrm{DM} \\
2.06 / \mathrm{US} \$\end{array}$ & $\begin{array}{c}\text { DM } \\
0.46 / \mathrm{US} \$\end{array}$ & $\begin{array}{c}\mathrm{DM} \\
1.87 / \mathrm{US} \$\end{array}$ & $\begin{array}{c}\mathrm{DM} \\
1.38 / \mathrm{US} \$\end{array}$ & $\begin{array}{c}\mathrm{DM} \\
3.30 / \mathrm{US} \$\end{array}$ \\
\hline exukus & UK/US\$ FX Rate & $£ 0.59 / \mathrm{US} \$$ & $£ 0.09$ & $£ 0.61 / \mathrm{US} \$$ & $£ 0.39 / \mathrm{US} \$$ & $£ 0.91 / \mathrm{US} \$$ \\
\hline exjpus & JP/US\$ FX Rate & $¥ 181.41 /$ US\$ & $¥ 68$ & $¥ 152.37 /$ US\$ & $¥ 83.69 / \mathrm{US} \$$ & $¥ 305.67 /$ US\$ \\
\hline FPS6CA & Equity Index Canada & 107.99 & 68.15 & 96.75 & 25.00 & 328.80 \\
\hline FPS6FR & Equity Index France & 94.90 & 86.56 & 81.70 & 11.10 & 364.50 \\
\hline FPS6WG & Equity Index Germany & 115.24 & 106.23 & 81.65 & 22.30 & 452.00 \\
\hline FPS6IT & Equity Index Italy & 91.70 & 79.90 & 82.10 & 8.70 & 330.70 \\
\hline FPS6JP & Equity Index Japan & 48.99 & 28.25 & 44.95 & 12.20 & 135.00 \\
\hline FPS6UK & Equity Index UK & 105.05 & 84.29 & 90.00 & 6.20 & 299.50 \\
\hline SPINDX & S\&P 500 Index & 442.32 & 404.49 & 286.28 & 63.54 & 1517.68 \\
\hline CPI_JP & CPI Japan & 85.29 & 16.43 & 88.45 & 37.10 & 102.20 \\
\hline CPI_UK & CPI UK & 427.95 & 192.05 & 420.70 & 89.30 & 723.90 \\
\hline CPI_US & CPI US & 118.11 & 42.38 & 118.25 & 42.60 & 185.20 \\
\hline CPI_G & CPI Germany & 100.08 & 22.11 & 100.2 & 58.02 & 134.8 \\
\hline R_3MT & 3 month US T-bills & $6.34 \%$ & $2.92 \%$ & $5.70 \%$ & $0.90 \%$ & $16.30 \%$ \\
\hline
\end{tabular}




\begin{tabular}{|c|c|c|c|c|c|c|}
\hline Variable Name & $\begin{array}{c}\text { Variable } \\
\text { Description }\end{array}$ & Mean & Std. Dev. & Median & Minimum & Maximum \\
\hline R_10YTB & $10 \mathrm{yr}$ US T-bonds & $7.99 \%$ & $2.48 \%$ & $7.55 \%$ & $3.33 \%$ & $15.32 \%$ \\
\hline R_AAA & AAA bond rate & $8.94 \%$ & $2.16 \%$ & $8.49 \%$ & $4.97 \%$ & $15.49 \%$ \\
\hline $\mathrm{R} \_\mathrm{Baa}$ & Baa bond rate & $10.04 \%$ & $2.49 \%$ & $9.48 \%$ & $6.19 \%$ & $17.18 \%$ \\
\hline RMBANK_a_JP & Discount rate Japan & $3.64 \%$ & $2.65 \%$ & $3.50 \%$ & $0.10 \%$ & $9.00 \%$ \\
\hline RMGBL_a_JP & Long Japanese bond & $5.26 \%$ & $2.53 \%$ & $5.56 \%$ & $0.49 \%$ & $8.89 \%$ \\
\hline RMGB10Y_a_GY & 10 yr German T-bond & $7.06 \%$ & $1.69 \%$ & $6.97 \%$ & $3.65 \%$ & $10.83 \%$ \\
\hline RMGBL_a_UK & 91 day UK gov & $8.92 \%$ & $3.31 \%$ & $9.21 \%$ & $3.33 \%$ & $16.28 \%$ \\
\hline RMGBSD_a_UK & 10 yr UK gov & $9.68 \%$ & $3.12 \%$ & $9.77 \%$ & $4.03 \%$ & $16.34 \%$ \\
\hline RMIB3S_a_UZ & 3 mo.Euribor rate & $8.26 \%$ & $3.51 \%$ & $8.24 \%$ & $2.13 \%$ & $18.92 \%$ \\
\hline M2SL & US M2 & $\$ 2,884.81 \mathrm{~b}$ & $\$ 1,425.59 \mathrm{~b}$ & $\$ 2,948.25 \mathrm{~b}$ & $\$ 810.30 \mathrm{~b}$ & $\$ 6,118.20 \mathrm{~b}$ \\
\hline M2_a_JP & JP M2 & $¥ 383,823 \mathrm{~b}$ & $¥ 191,783 \mathrm{~b}$ & $¥ 393,241 \mathrm{~b}$ & $¥ 82,303 \mathrm{~b}$ & $¥ 684,033 \mathrm{~b}$ \\
\hline M2NS_a_GY & German M2 & DM1614.7 b & DM667.2 b & DM1592.3 b & DM679.4 b & DM2727.01 b \\
\hline M2_a_UK & UK M2 money & $\begin{array}{c}£ 379.10 \\
\mathrm{~b}\end{array}$ & $£ 176.90 \mathrm{~b}$ & $£ 377.57 \mathrm{~b}$ & $£ 114.65 \mathrm{~b}$ & $£ 774.11 \mathrm{~b}$ \\
\hline M2_a_UZ & EU M2 Money & EU $2,796.6 \mathrm{~b}$ & EU1,151.02 b & EU2,723.18 b & EU1,071.05 b & $\mathrm{EU} 5,225.20 \mathrm{~b}$ \\
\hline JM2_a_UZ & M2 Index EU & 0.62 & 0.24 & 0.60 & 0.25 & 1.13 \\
\hline DUM_DIDMCA & DIDMCA dummy var. & 0.77 & & & 0 & 1 \\
\hline DUM_FDICIA & FDICIA dummy var. & 0.40 & & & 0 & 1 \\
\hline DUM_Basel & $\begin{array}{l}\text { Implementation of Basel } \\
\text { I var. }\end{array}$ & 0.36 & & & 0 & 1 \\
\hline DUM_Interstate & Riegle-Neal dummy var. & 0.32 & & & 0 & 1 \\
\hline DUM_GLBA & $\begin{array}{c}\text { Gramm-Leach-Bliley } \\
\text { dummy }\end{array}$ & 0.13 & & & 0 & 1 \\
\hline DUM_NBER & NBER recessions $\mathrm{var}$ & 0.23 & & & 0 & 1 \\
\hline RegDum & New regs var. & 0.01 & & & 0 & 1 \\
\hline
\end{tabular}


Table 2. Cyclicality in the Catastrophic Risk Measures of GPD

This table presents the correlation coefficients between the catastrophic risk measures of the GPD distribution and the variables associated with business cycle fluctuations. The cyclical variables are listed in Table 1. The catastrophic risk parameter estimates of the GPD are the location $(\mu-G P D)$, scale $(\sigma-G P D)$, and tail thickness $(\xi-$ $G P D$ ) parameters and $V a R 1 \%$-GPD is the $1 \%$ catastrophic value at risk. $\quad p$-values are given in parentheses.

\begin{tabular}{|c|c|c|c|c|c|c|c|c|}
\hline Variable Name & \multicolumn{2}{|c|}{$\mu-G P D$} & \multicolumn{2}{|c|}{$\sigma-G P D$} & \multicolumn{2}{|c|}{$\xi-G P D$} & \multicolumn{2}{|c|}{$1 \% V a R-G P D$} \\
\hline Consentiment & 0.00 & $(1.00)$ & -0.04 & $(0.49)$ & 0.07 & $(0.17)$ & 0.07 & $(0.16)$ \\
\hline Usunempl & 0.12 & $(0.02)$ & -0.07 & $(0.19)$ & -0.12 & $(0.02)$ & -0.23 & $(<.0001)$ \\
\hline RsvAst & -0.16 & $(0.01)$ & 0.38 & $(<.0001)$ & 0.06 & $(0.34)$ & 0.46 & $(<.0001)$ \\
\hline BusBnkrpcy & 0.02 & $(0.77)$ & 0.05 & $(0.38)$ & -0.07 & $(0.22)$ & 0.00 & $(0.96)$ \\
\hline GDP_US & -0.06 & $(0.28)$ & 0.09 & $(0.08)$ & 0.12 & $(0.02)$ & 0.25 & $(<.0001)$ \\
\hline IndstryIndex & -0.07 & $(0.22)$ & 0.07 & $(0.18)$ & 0.12 & $(0.03)$ & 0.23 & $(<.0001)$ \\
\hline exgeus & 0.06 & $(0.28)$ & -0.09 & $(0.07)$ & -0.10 & $(0.07)$ & -0.18 & $(0.00)$ \\
\hline exjpus & 0.06 & $(0.22)$ & -0.12 & $(0.02)$ & -0.12 & $(0.02)$ & -0.28 & $(<.0001)$ \\
\hline exukus & 0.06 & $(0.24)$ & -0.01 & $(0.78)$ & 0.07 & $(0.20)$ & 0.07 & $(0.21)$ \\
\hline FPS6CA & -0.08 & $(0.11)$ & 0.06 & $(0.22)$ & 0.11 & $(0.03)$ & 0.23 & $(<.0001)$ \\
\hline FPS6FR & -0.13 & $(0.01)$ & 0.12 & $(0.02)$ & 0.09 & $(0.08)$ & 0.30 & $(<.0001)$ \\
\hline FPS6WG & -0.12 & $(0.02)$ & 0.08 & $(0.15)$ & 0.09 & $(0.10)$ & 0.24 & $(<.0001)$ \\
\hline FPS6IT & -0.14 & $(0.01)$ & 0.11 & $(0.04)$ & 0.09 & $(0.07)$ & 0.30 & $(<.0001)$ \\
\hline FPS6JP & -0.16 & $(0.00)$ & 0.20 & $(0.00)$ & 0.10 & $(0.05)$ & 0.40 & $(<.0001)$ \\
\hline FPS6UK & -0.09 & $(0.08)$ & 0.08 & $(0.15)$ & 0.11 & $(0.03)$ & 0.25 & $(<.0001)$ \\
\hline SPINDX & -0.09 & $(0.09)$ & 0.06 & $(0.25)$ & 0.10 & $(0.07)$ & 0.22 & $(<.0001)$ \\
\hline CPI_JP & -0.05 & $(0.37)$ & 0.09 & $(0.10)$ & 0.11 & $(0.03)$ & 0.25 & $(<.0001)$ \\
\hline CPI_UK & -0.06 & $(0.27)$ & 0.11 & $(0.04)$ & 0.12 & $(0.02)$ & 0.27 & $(<.0001)$ \\
\hline CPI_US & -0.05 & $(0.32)$ & 0.10 & $(0.06)$ & 0.12 & $(0.02)$ & 0.26 & $(<.0001)$ \\
\hline CPI_G & -0.07 & $(0.22)$ & 0.07 & $(0.18)$ & 0.12 & $(0.03)$ & 0.24 & $(<.0001)$ \\
\hline R_3MT & -0.07 & $(0.20)$ & -0.13 & $(0.01)$ & -0.02 & $(0.71)$ & -0.12 & $(0.02)$ \\
\hline R_10YTB & -0.02 & $(0.69)$ & -0.12 & $(0.02)$ & -0.05 & $(0.31)$ & -0.14 & $(0.01)$ \\
\hline R_AAA & -0.03 & $(0.56)$ & -0.10 & $(0.05)$ & -0.05 & $(0.35)$ & -0.11 & $(0.03)$ \\
\hline R_Baa & -0.01 & $(0.83)$ & -0.11 & $(0.04)$ & -0.05 & $(0.36)$ & -0.13 & $(0.01)$ \\
\hline RMBANK_a_JP & -0.06 & $(0.29)$ & -0.01 & $(0.92)$ & -0.09 & $(0.07)$ & -0.08 & $(0.12)$ \\
\hline RMGBL_a_JP & 0.00 & $(0.94)$ & -0.03 & $(0.56)$ & -0.13 & $(0.02)$ & -0.16 & $(0.00)$ \\
\hline RMGB10Y_a_GY & -0.10 & $(0.06)$ & 0.04 & $(0.47)$ & -0.09 & $(0.08)$ & -0.01 & $(0.89)$ \\
\hline RMGBL_a_UK & 0.00 & $(0.95)$ & -0.08 & $(0.11)$ & -0.09 & $(0.10)$ & -0.19 & $(0.00)$ \\
\hline RMGBSD_a_UK & -0.10 & $(0.06)$ & 0.01 & $(0.82)$ & -0.03 & $(0.55)$ & 0.02 & $(0.70)$ \\
\hline RMIB3S_a_UZ & -0.06 & $(0.27)$ & 0.00 & $(1.00)$ & -0.09 & $(0.10)$ & -0.04 & $(0.39)$ \\
\hline M2_a_GY & -0.02 & $(0.79)$ & 0.10 & $(0.11)$ & 0.10 & $(0.11)$ & 0.15 & $(0.01)$ \\
\hline M2_a_JP & -0.07 & $(0.16)$ & 0.13 & $(0.01)$ & 0.12 & $(0.02)$ & 0.30 & $(<.0001)$ \\
\hline M2_a_UK & -0.01 & $(0.88)$ & 0.01 & $(0.91)$ & 0.14 & $(0.02)$ & 0.09 & $(0.17)$ \\
\hline M2_a_US & -0.06 & $(0.28)$ & 0.11 & $(0.03)$ & 0.12 & $(0.03)$ & 0.27 & $(<.0001)$ \\
\hline M2_a_UZ & -0.01 & $(0.89)$ & 0.11 & $(0.06)$ & 0.10 & $(0.10)$ & 0.17 & $(0.01)$ \\
\hline JM2_a_UZ & -0.01 & $(0.88)$ & 0.11 & $(0.06)$ & 0.10 & $(0.09)$ & 0.17 & $(0.00)$ \\
\hline DUM_DIDMCA & -0.07 & $(0.20)$ & 0.06 & $(0.28)$ & 0.11 & $(0.05)$ & 0.23 & $(<.0001)$ \\
\hline DUM_FDICIA & 0.00 & $(0.96)$ & 0.04 & $(0.44)$ & 0.09 & $(0.10)$ & 0.13 & $(0.01)$ \\
\hline DUM_Basel & 0.04 & $(0.43)$ & -0.04 & $(0.40)$ & 0.11 & $(0.03)$ & 0.04 & $(0.40)$ \\
\hline DUM_Interstate & 0.04 & $(0.46)$ & -0.07 & $(0.21)$ & 0.10 & $(0.05)$ & 0.01 & $(0.84)$ \\
\hline DUM_GLBA & -0.03 & $(0.57)$ & 0.06 & $(0.28)$ & 0.05 & $(0.36)$ & 0.14 & $(0.01)$ \\
\hline DUM_NBER & -0.08 & $(0.15)$ & 0.05 & $(0.31)$ & 0.02 & $(0.74)$ & 0.07 & $(0.16)$ \\
\hline RegDum & -0.12 & $(0.03)$ & 0.04 & $(0.43)$ & -0.04 & $(0.50)$ & 0.11 & $(0.04)$ \\
\hline
\end{tabular}


Table 3. Cyclicality in the Catastrophic Risk Measures of SGED

This table presents the correlation coefficients between the catastrophic risk measures of the SGED distribution and the variables associated with business cycle fluctuations. The cyclical variables are listed in Table 1. The catastrophic risk parameter estimates of the SGED are the mean ( $\mu-S G E D)$, standard deviation $(\sigma-S G E D)$, skewness $(\lambda-S G E D)$, and kurtosis $(\xi-S G E D)$ parameters and $V a R 1 \%-S G E D$ is the $1 \%$ catastrophic value at risk. $p$-values are given in parentheses.

\begin{tabular}{|c|c|c|c|c|c|}
\hline Variable Name & $\mu-S G E D$ & $\sigma-S G E D$ & $\lambda-S G E D$ & $\xi-S G E D$ & $1 \% V a R-S G E D$ \\
\hline Consentiment & $-0.03 \quad(0.63)$ & $0.01 \quad(0.88)$ & $-0.04 \quad(0.50)$ & $-0.32 \quad(<.0001)$ & $0.02 \quad(0.76)$ \\
\hline Usunempl & $(0.00)$ & $-0.03 \quad(0.57)$ & $0.09 \quad(0.08)$ & $0.20 \quad(0.00)$ & $-0.15 \quad(0.00)$ \\
\hline RsvAst & $(0.15)$ & $0.35 \quad(<.0001)$ & $-0.14 \quad(0.02)$ & $-0.52 \quad(<.0001)$ & $0.35 \quad(<.0001)$ \\
\hline BusBnkrpcy & $0.05 \quad(0.42)$ & $0.04 \quad(0.55)$ & $(0.99)$ & $0.12 \quad(0.05)$ & $\begin{array}{ll}0.00 \quad(0.99) \\
\end{array}$ \\
\hline GDP_US & $(0.87)$ & $0.26 \quad(<.0001)$ & $-0.04 \quad(0.42)$ & $-0.45 \quad(<.0001)$ & $0.20 \quad(<.0001)$ \\
\hline IndstryIndex & $-0.01 \quad(0.83)$ & $0.22 \quad(<.0001)$ & $-0.04 \quad(0.41)$ & $-0.40 \quad(<.0001)$ & $0.19 \quad(0.00)$ \\
\hline exgeus & $-0.01 \quad(0.78)$ & $-0.29 \quad(<.0001)$ & $-0.11 \quad(0.03)$ & $(<.0001)$ & $-0.20 \quad(0.00)$ \\
\hline exjpus & $(1.00)$ & $-0.29 \quad(<.0001)$ & $(0.91)$ & $0.51 \quad(<.0001)$ & $-0.23 \quad(<.0001)$ \\
\hline exukus & $(0.20)$ & $0.06 \quad(0.28)$ & $-0.06 \quad(0.26)$ & $-0.38 \quad(<.0001)$ & $\begin{array}{ll}-0.01 \quad(0.89) \\
\end{array}$ \\
\hline FPS6CA & $(0.81)$ & $0.23 \quad(<.0001)$ & $-0.05 \quad(0.37)$ & $(<.0001)$ & $0.20 \quad(<.0001)$ \\
\hline FPS6FR & $(0.61)$ & $0.31 \quad(<.0001)$ & $-0.07 \quad(0.18)$ & $(<.0001)$ & $(<.0001)$ \\
\hline FPS6WG & $(0.63)$ & $0.26 \quad(<.0001)$ & $-0.05 \quad(0.34)$ & $(<.0001)$ & $(<.0001)$ \\
\hline FPS6IT & $(0.41)$ & $0.29 \quad(<.0001)$ & $-0.08 \quad(0.15)$ & $(<.0001)$ & $(<.0001)$ \\
\hline FPS6JP & $(0.20)$ & $0.32 \quad(<.0001)$ & $-0.11 \quad(0.04)$ & $(<.0001)$ & $(<.0001)$ \\
\hline FPS6UK & $(0.78)$ & $0.26 \quad(<.0001)$ & $-0.04 \quad(0.46)$ & $(<.0001)$ & $(<.0001)$ \\
\hline SPINDX & $(0.80)$ & $0.24 \quad(<.0001)$ & $-0.04 \quad(0.51)$ & $(<.0001)$ & $(<.0001)$ \\
\hline CPI_JP & $(0.21)$ & $0.34 \quad(<.0001)$ & $0.00 \quad(1.00)$ & $(<.0001)$ & $(<.0001)$ \\
\hline CPI_UK & $(0.55)$ & $0.31 \quad(<.0001)$ & $-0.03 \quad(0.51)$ & $(<.0001)$ & $(<.0001)$ \\
\hline CPI_US & $(0.55)$ & $0.3 \quad(<.0001)$ & $-0.04 \quad(0.48)$ & $(<.0001)$ & $(<.0001)$ \\
\hline CPI_G & $(0.52)$ & $0.31 \quad(<.0001)$ & $\begin{array}{ll}-0.01 \quad(0.89) \\
\end{array}$ & $(<.0001)$ & $0.22 \quad(<.0001)$ \\
\hline R_3MT & $-0.09 \quad(0.10)$ & $-0.20 \quad(0.00)$ & $-0.01 \quad(0.84)$ & $(<.0001)$ & $-0.07 \quad(0.16)$ \\
\hline R_10YTB & $(0.67)$ & $-0.16 \quad(0.00)$ & $-0.01 \quad(0.80)$ & $(<.0001)$ & $-0.10 \quad(0.06)$ \\
\hline R_AAA & $-0.01 \quad(0.85)$ & $-0.12 \quad(0.02)$ & $-0.02 \quad(0.64)$ & $(<.0001)$ & $-0.07 \quad(0.22)$ \\
\hline R_Baa & $(0.71)$ & $-0.10 \quad(0.05)$ & $-0.01 \quad(0.88)$ & $(<.0001)$ & $-0.08 \quad(0.15)$ \\
\hline RMBANK_a_JP & $(0.62)$ & $-0.08 \quad(0.11)$ & $-0.03 \quad(0.63)$ & $(<.0001)$ & $(0.70)$ \\
\hline RMGBL_a_JP & $0.00 \quad(0.98)$ & $-0.14 \quad(0.01)$ & $0.01 \quad(0.85)$ & $(<.0001)$ & $-0.10 \quad(0.05)$ \\
\hline RMGB10Y_a_GY & $-0.09 \quad(0.07)$ & $-0.12 \quad(0.02)$ & $-0.10 \quad(0.07)$ & $(<.0001)$ & $(0.82)$ \\
\hline RMGBL_a_UK & $(0.64)$ & $-0.20 \quad(0.00)$ & $0.02 \quad(0.64)$ & $(<.0001)$ & $-0.13 \quad(0.01)$ \\
\hline RMGBSD_a_UK & $(0.36)$ & $0.00 \quad(0.99)$ & $-0.01 \quad(0.79)$ & $(<.0001)$ & $(0.30)$ \\
\hline RMIB3S_a_UZ & $(0.58)$ & $-0.07 \quad(0.19)$ & $-0.04 \quad(0.42)$ & $(<.0001)$ & $(0.92)$ \\
\hline M2_a_GY & $\begin{array}{ll}-0.02 & (0.79) \\
\end{array}$ & $0.15 \quad(0.01)$ & $-0.02 \quad(0.79)$ & $(<.0001)$ & $0.11 \quad(0.06)$ \\
\hline M2_a_JP & $(0.76)$ & $0.32 \quad(<.0001)$ & $-0.05 \quad(0.35)$ & $(<.0001)$ & $0.25 \quad(<.0001)$ \\
\hline M2_a_UK & $(0.63)$ & $\begin{array}{ll}0.07 & (0.29) \\
\end{array}$ & $(0.90)$ & $(<.0001)$ & $0.06 \quad(0.35)$ \\
\hline M2_a_US & $0.02 \quad(0.76)$ & $0.28 \quad(<.0001)$ & $-0.06 \quad(0.29)$ & $(<.0001)$ & $0.22 \quad(<.0001)$ \\
\hline M2_a_UZ & $\begin{array}{ll}-0.02 \quad(0.73) \\
\end{array}$ & $0.13 \quad(0.03)$ & $\begin{array}{ll}-0.04 & (0.49) \\
\end{array}$ & $(<.0001)$ & $0.11 \quad(0.08)$ \\
\hline JM2_a_UZ & $-0.02 \quad(0.7)$ & $0.13 \quad(0.03)$ & $-0.04 \quad(0.48)$ & $(<.0001)$ & $(0.08)$ \\
\hline DUM_DIDMCA & $0.04 \quad(0.46)$ & $0.26 \quad(<.0001)$ & $-0.06 \quad(0.27)$ & $(<.0001)$ & $(0.00)$ \\
\hline DUM_FDICIA & $(0.52)$ & $0.18 \quad(0.00)$ & $(0.90)$ & $(<.0001)$ & $(0.04)$ \\
\hline DUM_Basel & $(0.62)$ & $(0.27)$ & $(0.52)$ & $(<.0001)$ & $(0.86)$ \\
\hline DUM_Interstate & $(0.83)$ & $(0.98)$ & $(0.76)$ & $-0.26 \quad(<.0001)$ & $(0.69)$ \\
\hline DUM_GLBA & $(0.83)$ & $(0.01)$ & $-0.06 \quad(0.28)$ & $-0.17 \quad(0.00)$ & $(0.04)$ \\
\hline DUM_NBER & $\begin{array}{ll}-0.05 \quad(0.36) \\
\end{array}$ & $\begin{array}{ll}0.02 & (0.67) \\
\end{array}$ & $-0.07 \quad(0.21)$ & $0.19 \quad(0.00)$ & $(0.11)$ \\
\hline RegDum & $(0.21)$ & $(0.09)$ & $(0.42)$ & $(0.91)$ & $(0.01)$ \\
\hline
\end{tabular}


Table 4. Cyclicality in the Operational Risk Measures of GPD

This table presents the correlation coefficients between the operational risk measures of the GPD distribution and the variables associated with business cycle fluctuations. The cyclical variables are listed in Table 1. The operational risk parameter estimates of the GPD are the location ( $\mu$-ORGPD), scale $(\sigma-O R G P D)$, and tail thickness $(\xi-O R G P D)$ parameters and $V a R 1 \%$-ORGPD is the $1 \%$ operational value at risk. $p$-values are given in parentheses.

\begin{tabular}{|c|c|c|c|c|c|c|c|c|}
\hline \multirow{2}{*}{$\begin{array}{c}\text { Variable Name } \\
\text { Consentiment } \\
\end{array}$} & \multicolumn{2}{|c|}{$\mu-O R G P D$} & \multicolumn{2}{|c|}{$\sigma-O R G P D$} & \multicolumn{2}{|c|}{$\xi-O R G P D$} & \multicolumn{2}{|c|}{ 1\%VaR-ORGPD } \\
\hline & -0.29 & $(<.0001)$ & 0.02 & $(0.66)$ & 0.17 & $(0.00)$ & 0.24 & $(<.0001)$ \\
\hline Usunempl & 0.03 & $(0.58)$ & 0.05 & $(0.39)$ & -0.09 & $(0.10)$ & -0.05 & $(0.33)$ \\
\hline RsvAst & -0.38 & $(<.0001)$ & 0.35 & $(<.0001)$ & 0.04 & $(0.51)$ & 0.48 & $(<.0001)$ \\
\hline BusBnkrpcy & -0.17 & $(0.01)$ & 0.14 & $(0.02)$ & -0.20 & $(0.00)$ & 0.06 & $(0.36)$ \\
\hline GDP_US & -0.33 & $(<.0001)$ & 0.09 & $(0.08)$ & 0.23 & $(<.0001)$ & 0.42 & $(<.0001)$ \\
\hline IndstryIndex & -0.27 & $(<.0001)$ & 0.05 & $(0.30)$ & 0.21 & $(<.0001)$ & 0.35 & $(<.0001)$ \\
\hline exgeus & 0.23 & $(<.0001)$ & -0.11 & $(0.04)$ & -0.15 & $(0.01)$ & -0.33 & $(<.0001)$ \\
\hline exjpus & 0.41 & $(<.0001)$ & -0.11 & $(0.04)$ & -0.24 & $(<.0001)$ & -0.48 & $(<.0001)$ \\
\hline exukus & -0.40 & $(<.0001)$ & 0.11 & $(0.04)$ & 0.13 & $(0.01)$ & 0.36 & $(<.0001)$ \\
\hline FPS6CA & -0.26 & $(<.0001)$ & 0.03 & $(0.53)$ & 0.21 & $(<.0001)$ & 0.32 & $(<.0001)$ \\
\hline FPS6FR & -0.26 & $(<.0001)$ & 0.06 & $(0.26)$ & 0.19 & $(0.00)$ & 0.33 & $(<.0001)$ \\
\hline FPS6WG & -0.20 & $(0.00)$ & 0.01 & $(0.80)$ & 0.18 & $(0.00)$ & 0.24 & $(<.0001)$ \\
\hline FPS6IT & -0.26 & $(<.0001)$ & 0.04 & $(0.40)$ & 0.18 & $(0.00)$ & 0.30 & $(<.0001)$ \\
\hline FPS6JP & -0.45 & $(<.0001)$ & 0.17 & $(0.00)$ & 0.12 & $(0.03)$ & 0.44 & $(<.0001)$ \\
\hline FPS6UK & -0.28 & $(<.0001)$ & 0.04 & $(0.42)$ & 0.21 & $(<.0001)$ & 0.34 & $(<.0001)$ \\
\hline SPINDX & -0.21 & $(<.0001)$ & 0.03 & $(0.63)$ & 0.19 & $(0.00)$ & 0.27 & $(<.0001)$ \\
\hline CPI_JP & -0.47 & $(<.0001)$ & 0.14 & $(0.01)$ & 0.23 & $(<.0001)$ & 0.51 & $(<.0001)$ \\
\hline CPI_UK & -0.41 & $(<.0001)$ & 0.12 & $(0.02)$ & 0.23 & $(<.0001)$ & 0.48 & $(<.0001)$ \\
\hline CPI_US & -0.40 & $(<.0001)$ & 0.11 & $(0.04)$ & 0.23 & $(<.0001)$ & 0.47 & $(<.0001)$ \\
\hline CPI_G & -0.43 & $(<.0001)$ & 0.06 & $(0.30)$ & 0.23 & $(<.0001)$ & 0.43 & $(<.0001)$ \\
\hline R_3MT & 0.25 & $(<.0001)$ & -0.17 & $(0.00)$ & -0.13 & $(0.02)$ & -0.39 & $(<.0001)$ \\
\hline $\mathrm{R} \_10 \mathrm{YTB}$ & 0.12 & $(0.02)$ & -0.10 & $(0.06)$ & -0.11 & $(0.03)$ & -0.26 & $(<.0001)$ \\
\hline R_AAA & 0.09 & $(0.10)$ & -0.09 & $(0.09)$ & -0.11 & $(0.04)$ & -0.22 & $(<.0001)$ \\
\hline R_Baa & 0.10 & $(0.05)$ & -0.09 & $(0.10)$ & -0.11 & $(0.04)$ & -0.23 & $(<.0001)$ \\
\hline RMBANK_a_JP & 0.31 & $(<.0001)$ & -0.04 & $(0.40)$ & -0.25 & $(<.0001)$ & -0.38 & $(<.0001)$ \\
\hline RMGBL_a_JP & 0.25 & $(<.0001)$ & -0.03 & $(0.52)$ & -0.23 & $(<.0001)$ & -0.34 & $(<.0001)$ \\
\hline RMGB10Y_a_GY & 0.23 & $(<.0001)$ & -0.08 & $(0.13)$ & -0.19 & $(0.00)$ & -0.33 & $(<.0001)$ \\
\hline RMGBL_a_UK & 0.32 & $(<.0001)$ & -0.08 & $(0.13)$ & -0.25 & $(<.0001)$ & -0.42 & $(<.0001)$ \\
\hline RMGBSD_a_UK & 0.17 & $(0.00)$ & -0.01 & $(0.87)$ & -0.21 & $(<.0001)$ & -0.26 & $(<.0001)$ \\
\hline RMIB3S_a_UZ & 0.15 & $(0.00)$ & -0.03 & $(0.54)$ & -0.20 & $(0.00)$ & -0.23 & $(<.0001)$ \\
\hline M2_a_GY & -0.08 & $(0.16)$ & 0.06 & $(0.29)$ & 0.24 & $(<.0001)$ & 0.24 & $(<.0001)$ \\
\hline M2_a_JP & -0.40 & $(<.0001)$ & 0.13 & $(0.01)$ & 0.23 & $(<.0001)$ & 0.49 & $(<.0001)$ \\
\hline M2_a_UK & 0.08 & $(0.19)$ & 0.04 & $(0.56)$ & 0.19 & $(0.00)$ & 0.13 & $(0.03)$ \\
\hline M2_a_US & -0.37 & $(<.0001)$ & 0.13 & $(0.01)$ & 0.22 & $(<.0001)$ & 0.47 & $(<.0001)$ \\
\hline M2_a_UZ & -0.10 & $(0.09)$ & 0.10 & $(0.08)$ & 0.23 & $(<.0001)$ & 0.28 & $(<.0001)$ \\
\hline $\mathrm{JM} 2 \_\mathrm{a} \_\mathrm{UZ}$ & -0.11 & $(0.08)$ & 0.10 & $(0.09)$ & 0.23 & $(<.0001)$ & 0.28 & $(<.0001)$ \\
\hline DUM_DIDMCA & -0.43 & $(<.0001)$ & 0.07 & $(0.16)$ & 0.18 & $(0.00)$ & 0.40 & $(<.0001)$ \\
\hline DUM_FDICIA & -0.21 & $(<.0001)$ & 0.03 & $(0.52)$ & 0.22 & $(<.0001)$ & 0.32 & $(<.0001)$ \\
\hline DUM_Basel & -0.15 & $(0.00)$ & -0.03 & $(0.54)$ & 0.22 & $(<.0001)$ & 0.23 & $(<.0001)$ \\
\hline DUM_Interstate & -0.07 & $(0.21)$ & -0.07 & $(0.20)$ & 0.18 & $(0.00)$ & 0.11 & $(0.04)$ \\
\hline DUM_GLBA & -0.10 & $(0.06)$ & 0.08 & $(0.13)$ & 0.11 & $(0.05)$ & 0.22 & $(<.0001)$ \\
\hline DUM_NBER & 0.14 & $(0.01)$ & -0.02 & $(0.73)$ & -0.09 & $(0.08)$ & -0.10 & $(0.06)$ \\
\hline RegDum & -0.05 & $(0.39)$ & 0.07 & $(0.18)$ & 0.01 & $(0.92)$ & 0.08 & $(0.11)$ \\
\hline
\end{tabular}


Table 5. Cyclicality in the Operational Risk Measures of SGED

This table presents the correlation coefficients between the operational risk measures of the SGED distribution and the variables associated with business cycle fluctuations. The cyclical variables are listed in Table 1 . The operational risk parameter estimates of the SGED are the mean $(\mu$-ORSGED), standard deviation $(\sigma-O R S G E D)$, skewness $(\lambda$-ORSGED), and kurtosis $(\xi$-ORSGED) parameters and VaR1\%-ORSGED is the $1 \%$ operational value at risk. $p$-values are given in parentheses.

\begin{tabular}{|c|c|c|c|c|c|c|c|}
\hline \multirow{2}{*}{$\begin{array}{c}\text { Variable Name } \\
\text { Consentiment }\end{array}$} & $\mu-O R S G E D$ & $\sigma-O R S G E D$ & \multicolumn{2}{|c|}{$\lambda$-ORSGED } & $\xi-O R S G E D$ & \multicolumn{2}{|c|}{$\begin{array}{c}\text { 1\%VaR } \\
\text { ORSGED }\end{array}$} \\
\hline & $-0.05 \quad(0.33)$ & $0.30 \quad(<.0001)$ & 0.01 & $(0.81)$ & $-0.21 \quad(<.0001)$ & 0.31 & $(<.0001)$ \\
\hline Usunempl & $-0.01 \quad(0.81)$ & $-0.06 \quad(0.25)$ & 0.04 & $(0.43)$ & $\begin{array}{ll}-0.01 & (0.82)\end{array}$ & -0.06 & $(0.29)$ \\
\hline RsvAst & $\begin{array}{ll}0.00 \quad(0.94) \\
\end{array}$ & $0.58 \quad(<.0001)$ & 0.05 & $(0.38)$ & $-0.40 \quad(<.0001)$ & 0.54 & $(<.0001)$ \\
\hline BusBnkrpcy & $0.04 \quad(0.52)$ & $0.17 \quad(0.01)$ & 0.06 & $(0.35)$ & $0.11 \quad(0.07)$ & 0.15 & $(0.01)$ \\
\hline GDP_US & $-0.07 \quad(0.17)$ & $0.44 \quad(<.0001)$ & 0.01 & $(0.91)$ & $-0.36 \quad(<.0001)$ & 0.44 & $(<.0001)$ \\
\hline IndstryIndex & $-0.08 \quad(0.13)$ & $0.35 \quad(<.0001)$ & -0.01 & $(0.82)$ & $(<.0001)$ & 0.36 & $(<.0001)$ \\
\hline exgeus & $0.01 \quad(0.91)$ & $-0.37 \quad(<.0001)$ & -0.09 & $(0.09)$ & $(<.0001)$ & -0.34 & $(<.0001)$ \\
\hline exjpus & $0.06 \quad(0.27)$ & $-0.54 \quad(<.0001)$ & -0.03 & $(0.51)$ & $(<.0001)$ & -0.52 & $(<.0001)$ \\
\hline exukus & $-0.10 \quad(0.06)$ & $0.43 \quad(<.0001)$ & 0.03 & $(0.59)$ & $-0.27 \quad(<.0001)$ & 0.44 & $(<.0001)$ \\
\hline FPS6CA & $-0.06 \quad(0.27)$ & $(<.0001)$ & 0.00 & $(0.95)$ & $(<.0001)$ & 0.34 & $(<.0001)$ \\
\hline FPS6FR & $-0.06 \quad(0.22)$ & $0.34 \quad(<.0001)$ & 0.00 & $(0.99)$ & $(<.0001)$ & 0.34 & $(<.0001)$ \\
\hline FPS6WG & $-0.05 \quad(0.32)$ & $0.25 \quad(<.0001)$ & 0.00 & $(0.99)$ & $-0.22 \quad(<.0001)$ & 0.26 & $(<.0001)$ \\
\hline FPS6IT & $-0.06 \quad(0.23)$ & $(<.0001)$ & 0.00 & $(0.96)$ & $(<.0001)$ & 0.33 & $(<.0001)$ \\
\hline FPS6JP & $-0.03 \quad(0.60)$ & $(<.0001)$ & 0.08 & $(0.13)$ & $-0.31 \quad(<.0001)$ & 0.54 & $(<.0001)$ \\
\hline FPS6UK & $-0.06 \quad(0.25)$ & $(<.0001)$ & 0.00 & $(0.96)$ & $(<.0001)$ & 0.36 & $(<.0001)$ \\
\hline SPINDX & $-0.06 \quad(0.27)$ & $(<.0001)$ & -0.01 & $(0.82)$ & $(<.0001)$ & 0.28 & $(<.0001)$ \\
\hline CPI_JP & $-0.08 \quad(0.12)$ & $(<.0001)$ & 0.07 & $(0.16)$ & $(<.0001)$ & 0.57 & $(<.0001)$ \\
\hline CPI_UK & $\begin{array}{ll}-0.08 \quad(0.13) \\
\end{array}$ & $0.53 \quad(<.0001)$ & 0.03 & $(0.55)$ & $(<.0001)$ & 0.52 & $(<.0001)$ \\
\hline CPI_US & $-0.08 \quad(0.13)$ & $0.52 \quad(<.0001)$ & 0.03 & $(0.62)$ & $(<.0001)$ & 0.51 & $(<.0001)$ \\
\hline CPI_G & $-0.07 \quad(0.18)$ & $0.51 \quad(<.0001)$ & 0.06 & $(0.31)$ & $(<.0001)$ & 0.50 & $(<.0001)$ \\
\hline R_3MT & $0.06 \quad(0.29)$ & $-0.38 \quad(<.0001)$ & 0.03 & $(0.59)$ & $(0.00)$ & -0.38 & $(<.0001)$ \\
\hline R_10YTB & $0.03 \quad(0.57)$ & $(<.0001)$ & 0.05 & $(0.37)$ & $(0.05)$ & -0.23 & $(<.0001)$ \\
\hline R_AAA & $0.01 \quad(0.82)$ & $(<.0001)$ & 0.04 & $(0.42)$ & $(0.12)$ & -0.20 & $(0.00)$ \\
\hline $\mathrm{R} \_\mathrm{Baa}$ & $0.01 \quad(0.78)$ & $(<.0001)$ & 0.05 & $(0.39)$ & $0.07 \quad(0.16)$ & -0.21 & $(<.0001)$ \\
\hline RMBANK_a_JP & $\begin{array}{ll}0.06 & (0.23) \\
\end{array}$ & $(<.0001)$ & -0.01 & $(0.78)$ & $0.38 \quad(<.0001)$ & -0.39 & $(<.0001)$ \\
\hline RMGBL_a_JP & $0.06 \quad(0.22)$ & $(<.0001)$ & 0.02 & $(0.67)$ & $(<.0001)$ & -0.34 & $(<.0001)$ \\
\hline RMGB10Y_a_GY & $0.06 \quad(0.26)$ & $(<.0001)$ & -0.02 & $(0.77)$ & $(<.0001)$ & -0.32 & $(<.0001)$ \\
\hline RMGBL_a_UK & $(0.20)$ & $(<.0001)$ & 0.03 & $(0.54)$ & $0.29 \quad(<.0001)$ & -0.42 & $(<.0001)$ \\
\hline RMGBSD_a_UK & $(0.25)$ & $(<.0001)$ & 0.06 & $(0.22)$ & $0.15 \quad(0.00)$ & -0.23 & $(<.0001)$ \\
\hline RMIB3S_a_UZ & $0.03 \quad(0.54)$ & $-0.22 \quad(<.0001)$ & 0.00 & $(0.96)$ & $0.23 \quad(<.0001)$ & -0.22 & $(<.0001)$ \\
\hline M2_a_GY & $-0.04 \quad(0.53)$ & $0.20 \quad(0.00)$ & -0.06 & $(0.30)$ & $-0.30 \quad(<.0001)$ & 0.20 & $(0.00)$ \\
\hline M2_a_JP & $-0.08 \quad(0.15)$ & $0.53 \quad(<.0001)$ & 0.02 & $(0.64)$ & $(<.0001)$ & 0.52 & $(<.0001)$ \\
\hline M2_a_UK & $\begin{array}{ll}-0.03 \quad(0.64) \\
\end{array}$ & $0.03 \quad(0.62)$ & -0.05 & $(0.42)$ & $(<.0001)$ & 0.03 & $(0.60)$ \\
\hline M2_a_US & $-0.09 \quad(0.10)$ & $0.50 \quad(<.0001)$ & 0.00 & $(0.95)$ & $(<.0001)$ & 0.50 & $(<.0001)$ \\
\hline M2_a_UZ & $(0.49)$ & $0.23 \quad(<.0001)$ & -0.07 & $(0.24)$ & $(<.0001)$ & 0.23 & $(<.0001)$ \\
\hline JM2_a_UZ & $-0.04 \quad(0.48)$ & $0.24 \quad(<.0001)$ & -0.07 & $(0.24)$ & $-0.31 \quad(<.0001)$ & 0.24 & $(<.0001)$ \\
\hline DUM_DIDMCA & $-0.08 \quad(0.11)$ & $0.47 \quad(<.0001)$ & 0.03 & $(0.58)$ & $(<.0001)$ & 0.47 & $(<.0001)$ \\
\hline DUM_FDICIA & $(0.22)$ & $0.30 \quad(<.0001)$ & -0.01 & $(0.88)$ & $(<.0001)$ & 0.31 & $(<.0001)$ \\
\hline DUM_Basel & $-0.05 \quad(0.33)$ & $0.20 \quad(0.00)$ & -0.03 & $(0.58)$ & $-0.21 \quad(<.0001)$ & 0.21 & $(<.0001)$ \\
\hline DUM_Interstate & $-0.03 \quad(0.62)$ & $(0.08)$ & -0.01 & $(0.83)$ & $\begin{array}{ll}-0.17 \quad(0.00) \\
\end{array}$ & 0.10 & $(0.06)$ \\
\hline DUM_GLBA & $(0.24)$ & $(0.00)$ & -0.05 & $(0.32)$ & $-0.13 \quad(0.01)$ & 0.18 & $(0.00)$ \\
\hline DUM_NBER & $\begin{array}{ll}-0.01 \quad(0.89) \\
\end{array}$ & $-0.14 \quad(0.01)$ & -0.04 & $(0.41)$ & $(0.00)$ & -0.13 & $(0.01)$ \\
\hline RegDum & $-0.06 \quad(0.24)$ & $(0.20)$ & -0.02 & $(0.71)$ & $(0.28)$ & 0.08 & $(0.11)$ \\
\hline
\end{tabular}


Table 6. Cyclicality in the Catastrophic and Operational Risk Measures of SGT

This table presents the correlation coefficients between the catastrophic and operational risk measures of the SGT distribution and the variables associated with business cycle fluctuations. The cyclical variables are listed in Table 1 . The $1 \%$ catastrophic VaR of SGT is denoted by $1 \%$ VaR-SGT and the $1 \%$ operational VaR of SGT is denoted by $1 \%$ VaR-ORSGT. $p$-values are given in parentheses.

\begin{tabular}{|c|c|c|c|c|}
\hline \multirow{2}{*}{$\begin{array}{c}\text { Variable Name } \\
\text { Consentiment }\end{array}$} & \multicolumn{2}{|c|}{ 1\%VaR-SGT } & \multicolumn{2}{|c|}{ 1\%VaR-ORSGT } \\
\hline & 0.03 & $(0.69)$ & 0.31 & $(<.0001)$ \\
\hline Usunempl & -0.14 & $(0.00)$ & -0.05 & $(0.93)$ \\
\hline RsvAst & 0.30 & $(<.0001)$ & 0.54 & $(<.0001)$ \\
\hline BusBnkrpcy & 0.00 & $(0.87)$ & 0.14 & $(0.00)$ \\
\hline GDP_US & 0.21 & $(<.0001)$ & 0.44 & $(<.0001)$ \\
\hline IndstryIndex & 0.20 & $(0.00)$ & 0.36 & $(<.0001)$ \\
\hline exgeus & -0.22 & $(0.00)$ & -0.34 & $(0.00)$ \\
\hline exjpus & -0.25 & $(<.0001)$ & -0.52 & $(<.0001)$ \\
\hline exukus & -0.01 & $(0.72)$ & 0.44 & $(<.0001)$ \\
\hline FPS6CA & 0.22 & $(<.0001)$ & 0.34 & $(<.0001)$ \\
\hline FPS6FR & 0.27 & $(<.0001)$ & 0.35 & $(<.0001)$ \\
\hline FPS6WG & 0.23 & $(<.0001)$ & 0.26 & $(0.00)$ \\
\hline FPS6IT & 0.28 & $(<.0001)$ & 0.33 & $(<.0001)$ \\
\hline FPS6JP & 0.31 & $(<.0001)$ & 0.54 & $(<.0001)$ \\
\hline FPS6UK & 0.23 & $(<.0001)$ & 0.36 & $(<.0001)$ \\
\hline SPINDX & 0.21 & $(<.0001)$ & 0.28 & $(0.00)$ \\
\hline CPI_JP & 0.20 & $(<.0001)$ & 0.58 & $(<.0001)$ \\
\hline CPI_UK & 0.22 & $(<.0001)$ & 0.52 & $(<.0001)$ \\
\hline CPI_US & 0.23 & $(<.0001)$ & 0.51 & $(<.0001)$ \\
\hline CPI_G & 0.21 & $(<.0001)$ & 0.50 & $(<.0001)$ \\
\hline $\mathrm{R} \_3 \mathrm{MT}$ & -0.06 & $(0.17)$ & -0.39 & $(<.0001)$ \\
\hline R_10YTB & -0.11 & $(0.14)$ & -0.23 & $(0.01)$ \\
\hline R_AAA & -0.06 & $(0.21)$ & -0.20 & $(0.06)$ \\
\hline R_Baa & -0.08 & $(0.15)$ & -0.21 & $(0.03)$ \\
\hline RMBANK_a_JP & -0.01 & $(0.72)$ & -0.39 & $(<.0001)$ \\
\hline RMGBL_a_JP & -0.10 & $(0.05)$ & -0.34 & $(<.0001)$ \\
\hline RMGB10Y_a_GY & 0.01 & $(0.79)$ & -0.32 & $(<.0001)$ \\
\hline RMGBL_a_UK & -0.14 & $(0.01)$ & -0.43 & $(<.0001)$ \\
\hline RMGBSD_a_UK & 0.05 & $(0.30)$ & -0.23 & $(0.01)$ \\
\hline RMIB3S_a_UZ & -0.01 & $(0.92)$ & -0.22 & $(0.01)$ \\
\hline M2_a_GY & 0.12 & $(0.06)$ & 0.20 & $(0.19)$ \\
\hline M2_a_JP & 0.24 & $(<.0001)$ & 0.53 & $(<.0001)$ \\
\hline M2_a_UK & 0.05 & $(0.44)$ & 0.04 & $(0.29)$ \\
\hline M2_a_US & 0.23 & $(<.0001)$ & 0.50 & $(<.0001)$ \\
\hline M2_a_UZ & 0.12 & $(0.07)$ & 0.24 & $(0.08)$ \\
\hline JM2_a_UZ & 0.12 & $(0.07)$ & 0.24 & $(0.07)$ \\
\hline DUM_DIDMCA & 0.22 & $(0.00)$ & 0.47 & $(<.0001)$ \\
\hline DUM_FDICIA & 0.12 & $(0.04)$ & 0.31 & $(0.00)$ \\
\hline DUM_Basel & 0.01 & $(0.81)$ & 0.21 & $(0.04)$ \\
\hline DUM_Interstate & -0.02 & $(0.69)$ & 0.10 & $(0.62)$ \\
\hline DUM_GLBA & 0.12 & $(0.04)$ & 0.18 & $(0.05)$ \\
\hline DUM_NBER & 0.10 & $(0.10)$ & -0.13 & $(0.02)$ \\
\hline RegDum & 0.13 & $(0.01)$ & 0.08 & $(0.23)$ \\
\hline
\end{tabular}


Figure 1. Location, Scale, and Shape Parameters of the GPD

Figures 1A, 1B, and 1C present the time-series plot of the location ( $\mu$-GPD), scale ( $\sigma$-GPD), and shape ( $\xi$-GPD) parameters of the generalized Pareto distribution (GPD), respectively. The parameters are estimated by maximizing the log-likelihood function of the GPD density based on the lowest $10 \%$ of all monthly equity returns of financial institutions. The extremes (minimal returns) are obtained from the cross-section of stock returns for each month from April 1973 to June 2003.
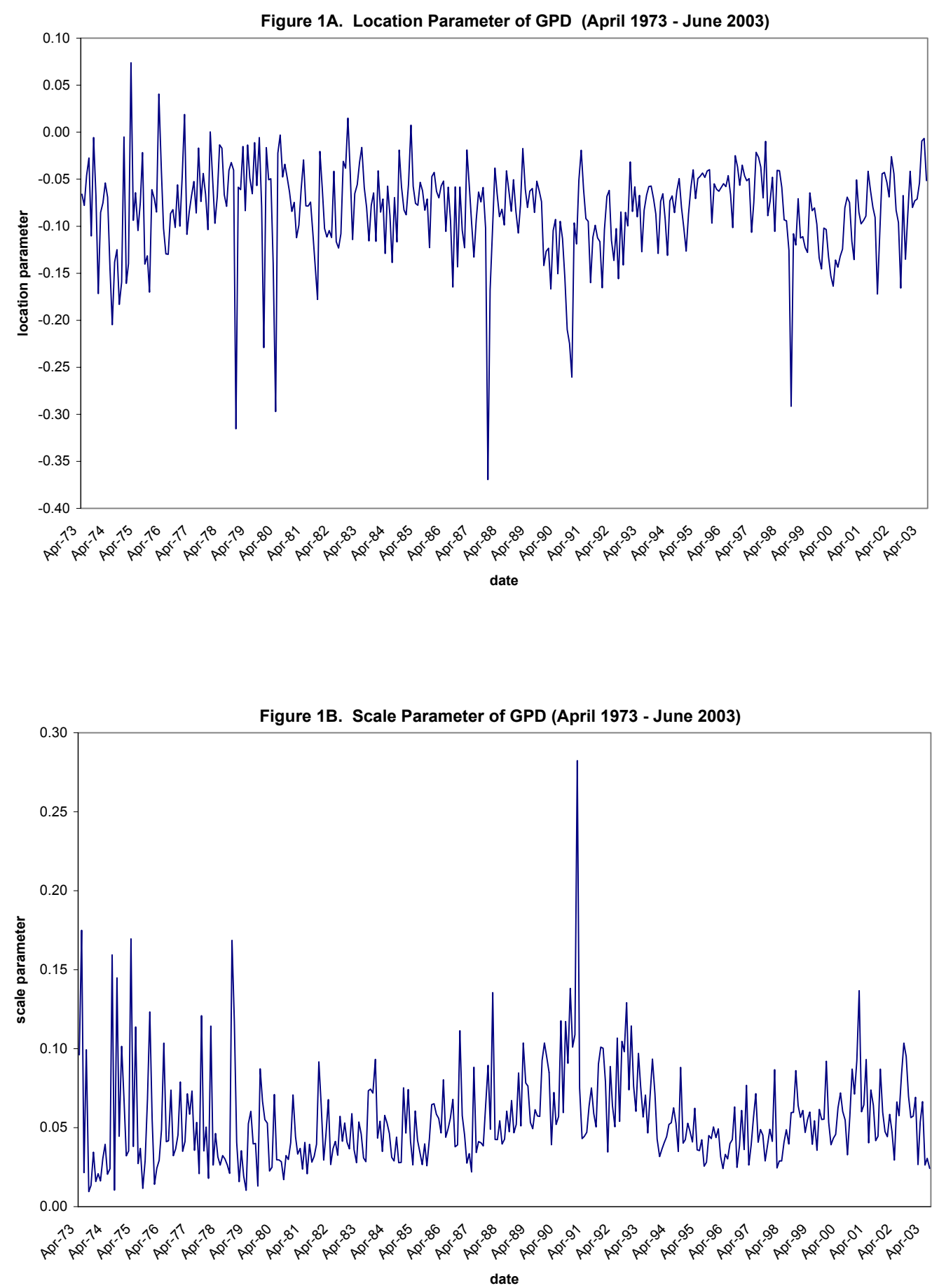


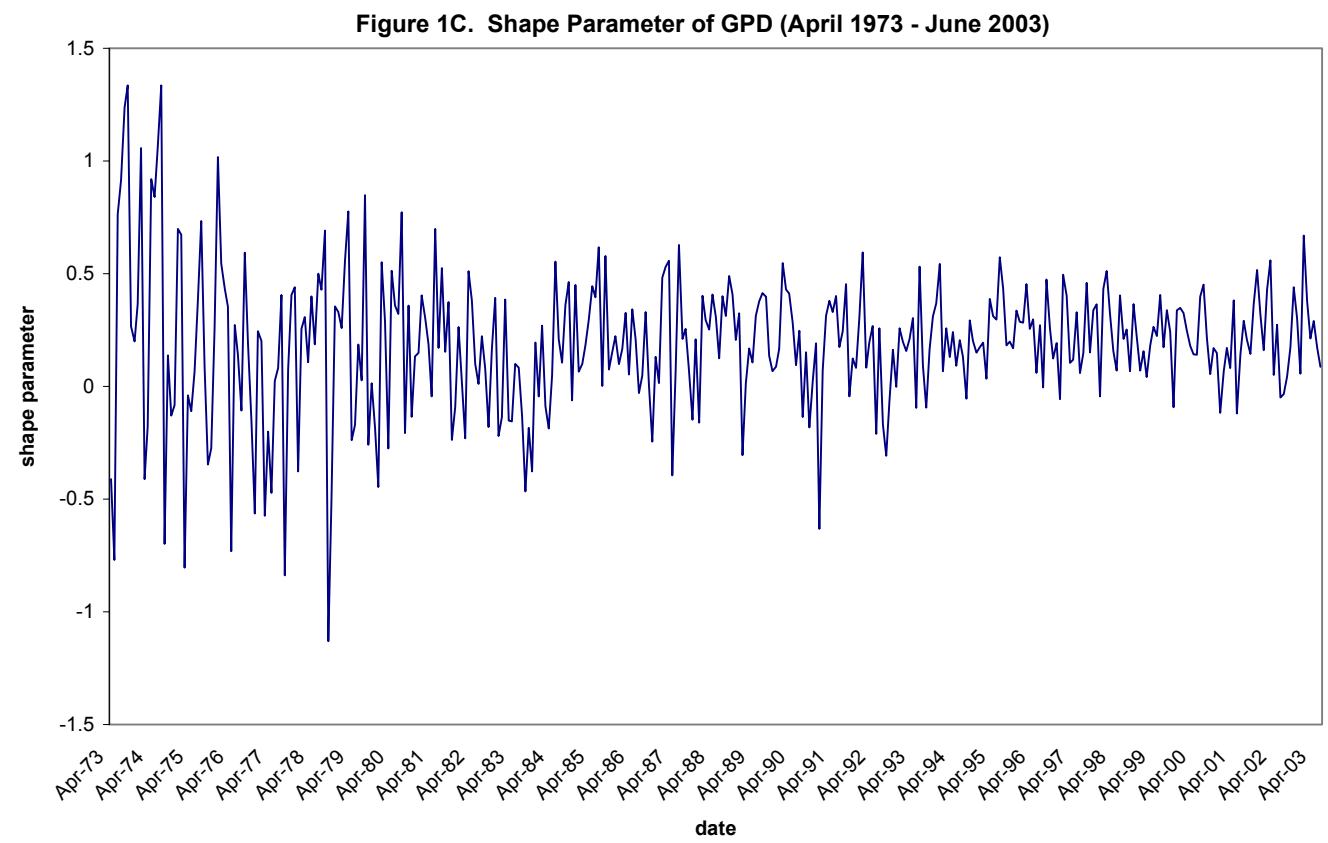


Figure 2. Mean, Standard Deviation, Skewness, and Tail-Thickness Parameters of the SGED

Figures $2 \mathrm{~A}, 2 \mathrm{~B}, 2 \mathrm{C}$, and 2D present the time-series of the mean ( $\mu$-SGED), standard deviation ( $\sigma$-SGED), skewness ( $\lambda$-SGED), and tail-thickness ( $\xi$-SGED) parameters of the skewed generalized error distribution (SGED), respectively. The parameters are estimated by maximizing the log-likelihood function of the SGED density based on the cross-section of all monthly equity returns of financial institutions for each month from April 1973 to June 2003.
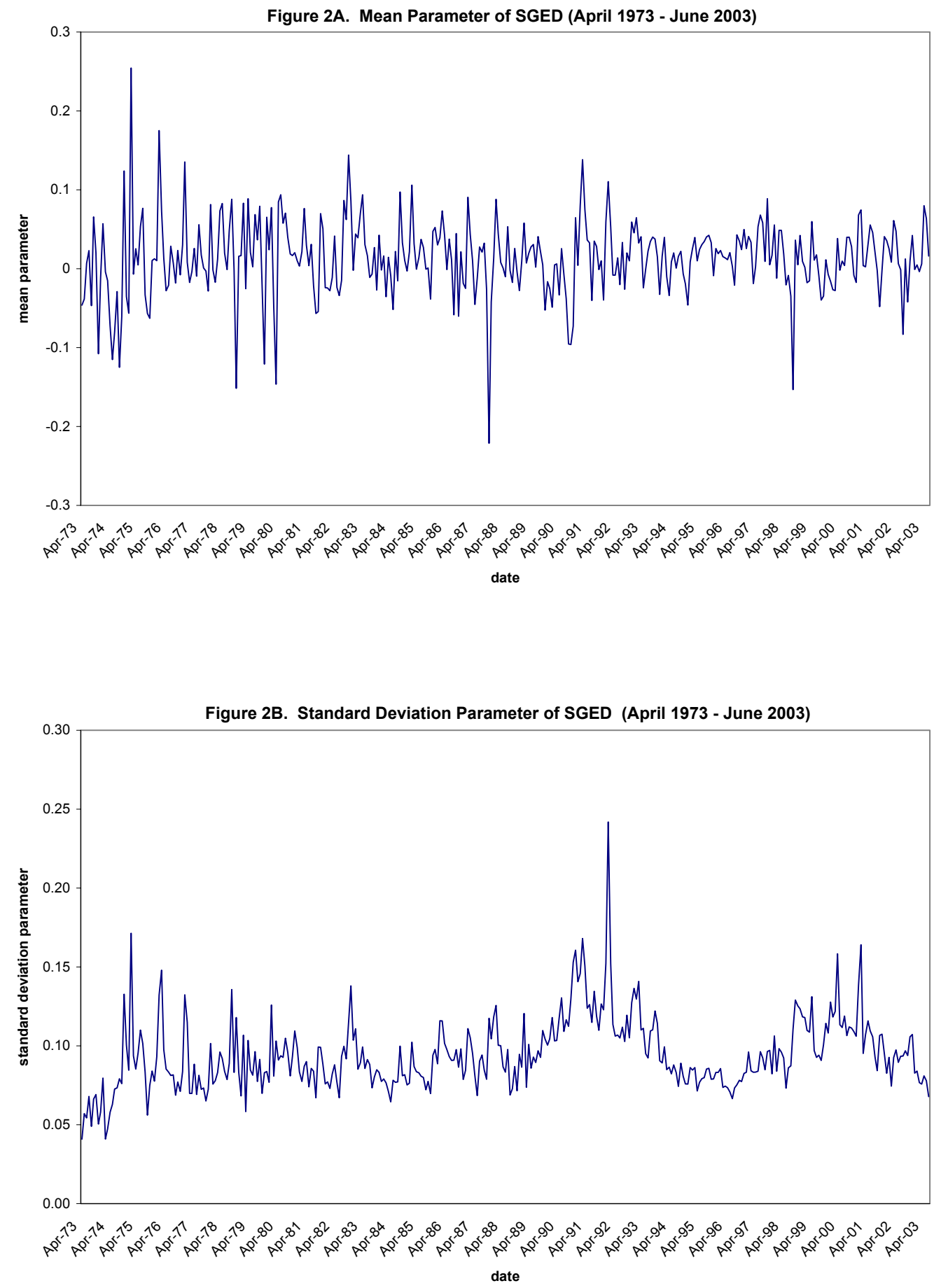

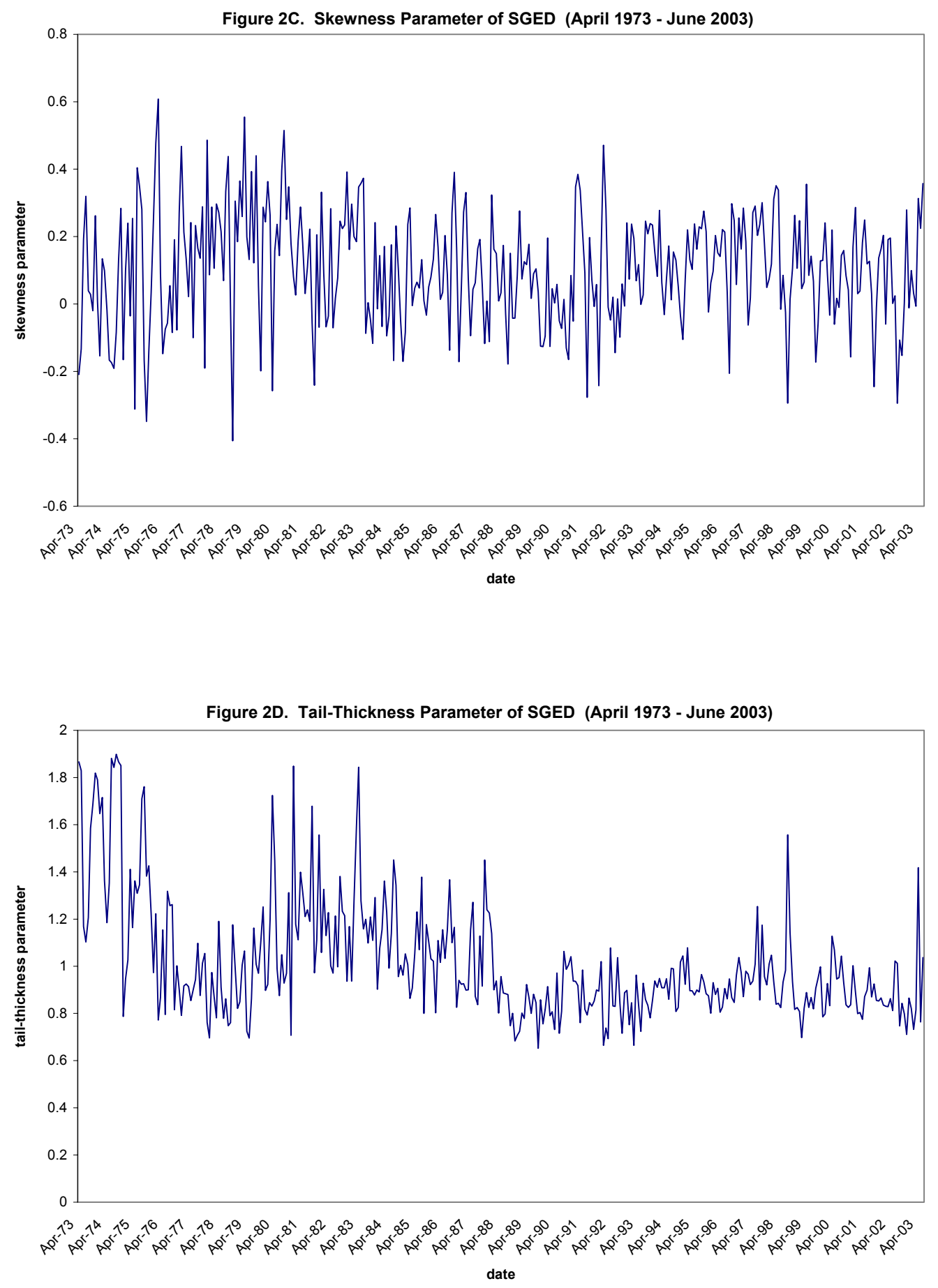
Figure 3. 1\% Catastrophic VaR Measures of GPD and SGED

Figure 3A presents the $1 \%$ catastrophic VaR measures of the GPD and SGED distributions over the sample period April 1973-June 2003. The catastrophic VaR measures are calculated based on the maximum likelihood parameter estimates of the GPD and SGED distributions. Figure 3B shows the difference between the $1 \% \mathrm{VaR}$ of SGED and the $1 \% \mathrm{VaR}$ of GPD.
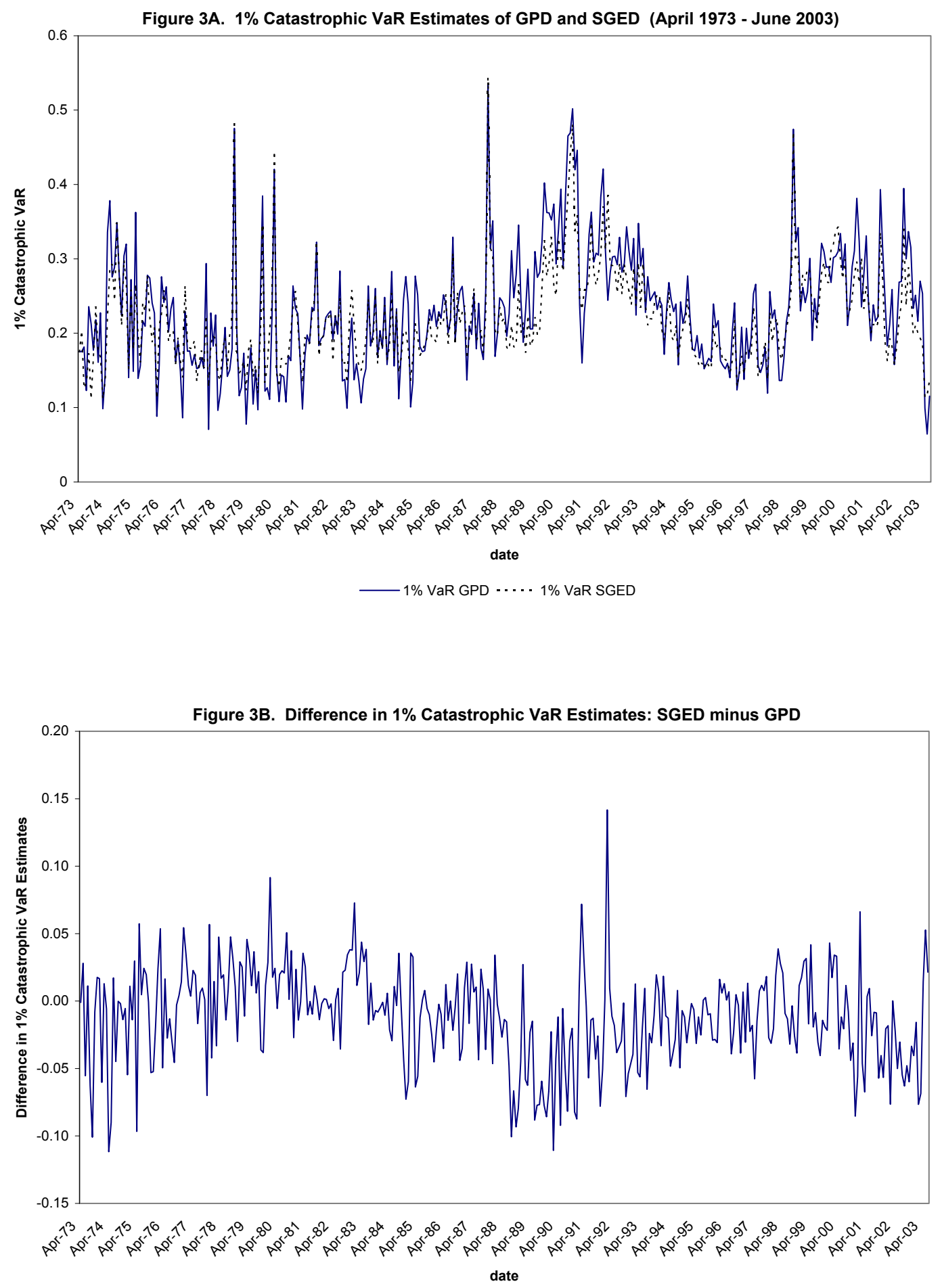
Figure 4. 1\% Catastrophic and Operational VaR Measures of GPD and SGED

Figures $4 \mathrm{~A}$ and $4 \mathrm{~B}$ present the $1 \%$ catastrophic and operational VaR measures of the GPD and SGED distribution, respectively. For both distributions, the operational $\mathrm{VaR}$ measures plot below the catastrophic VaR measures over the sample period April 1973-June 2003.
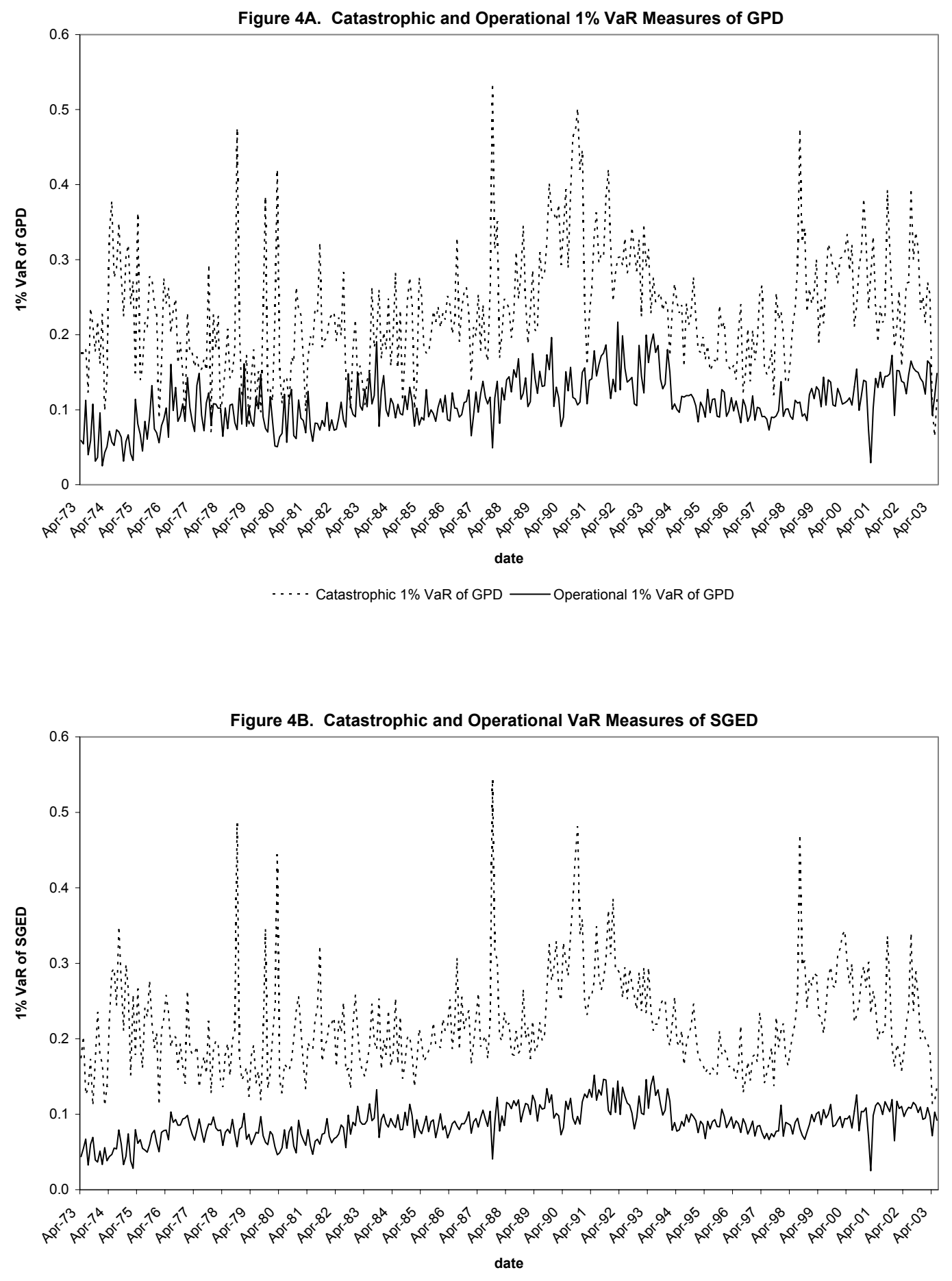

Catastrophic $1 \%$ VaR of SGED — Operational $1 \%$ VaR of SGED 
Figure 5. Ratio of Operational VaR to Catastrophic VaR of GPD and SGED

Figures $5 \mathrm{~A}$ and $5 \mathrm{~B}$ present the ratios of the $1 \%$ operational $\mathrm{VaR}$ to the $1 \%$ catastrophic VaR obtained from the GPD and SGED distributions, respectively. The mean monthly ratio over the entire sample period (April 1973-June 2003) is 0.52 for the GPD and 0.42 for the SGED distribution.
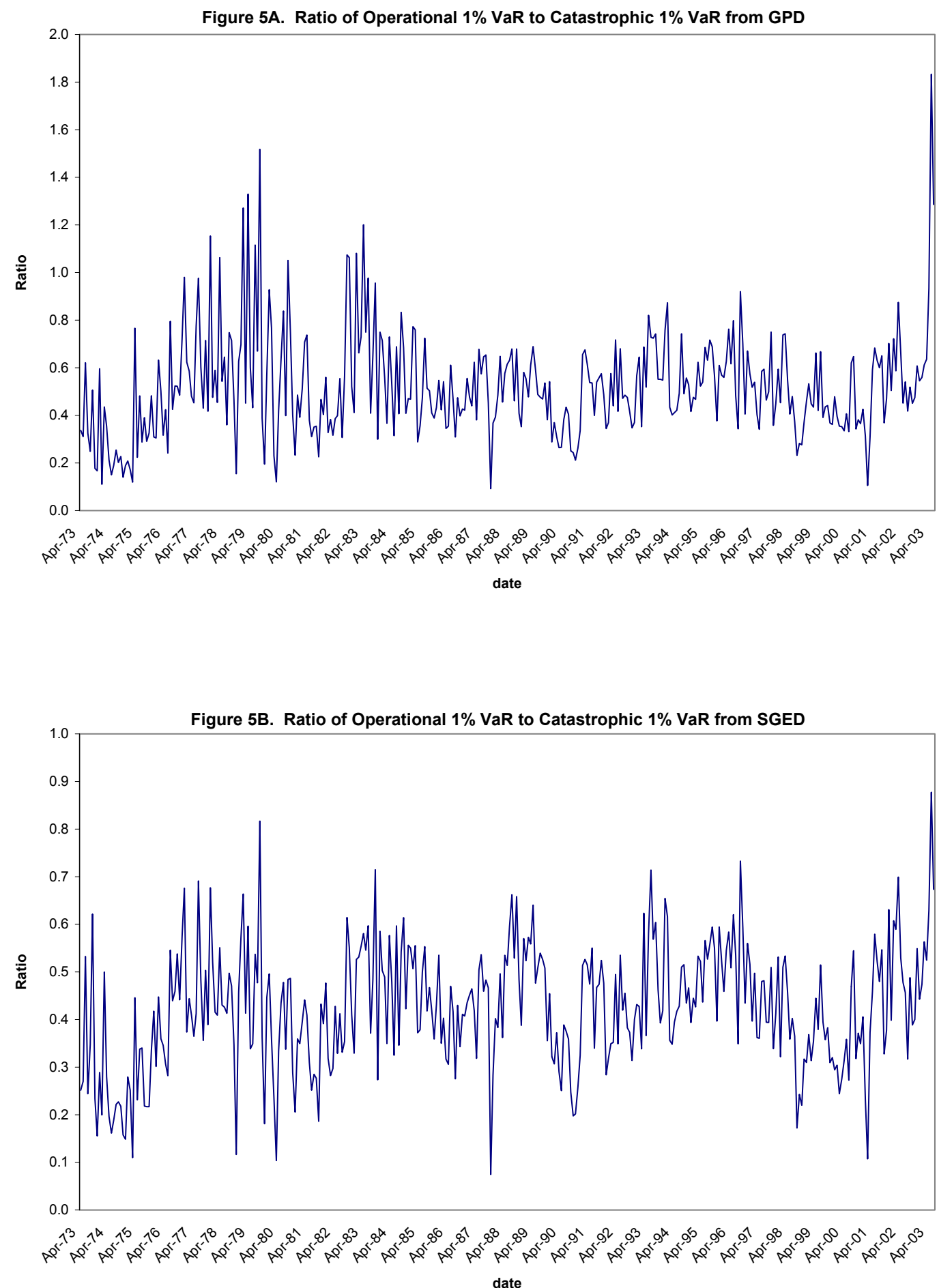
Figure 6. Conditional Catastrophic and Operational 1\% VaR Measures

Figures $6 \mathrm{~A}$ and $6 \mathrm{~B}$ present the $1 \%$ conditional catastrophic and operational VaR measures for major financial institutions based on the maximum likelihood parameter estimates of the MA(1) SGED GJRGARCH-in-mean model. The conditional VaR measures are estimated using the value-weighted portfolio returns for major recognizable financial institutions, and for each of the three industry sectors (depository institutions, insurance companies, and securities firms).
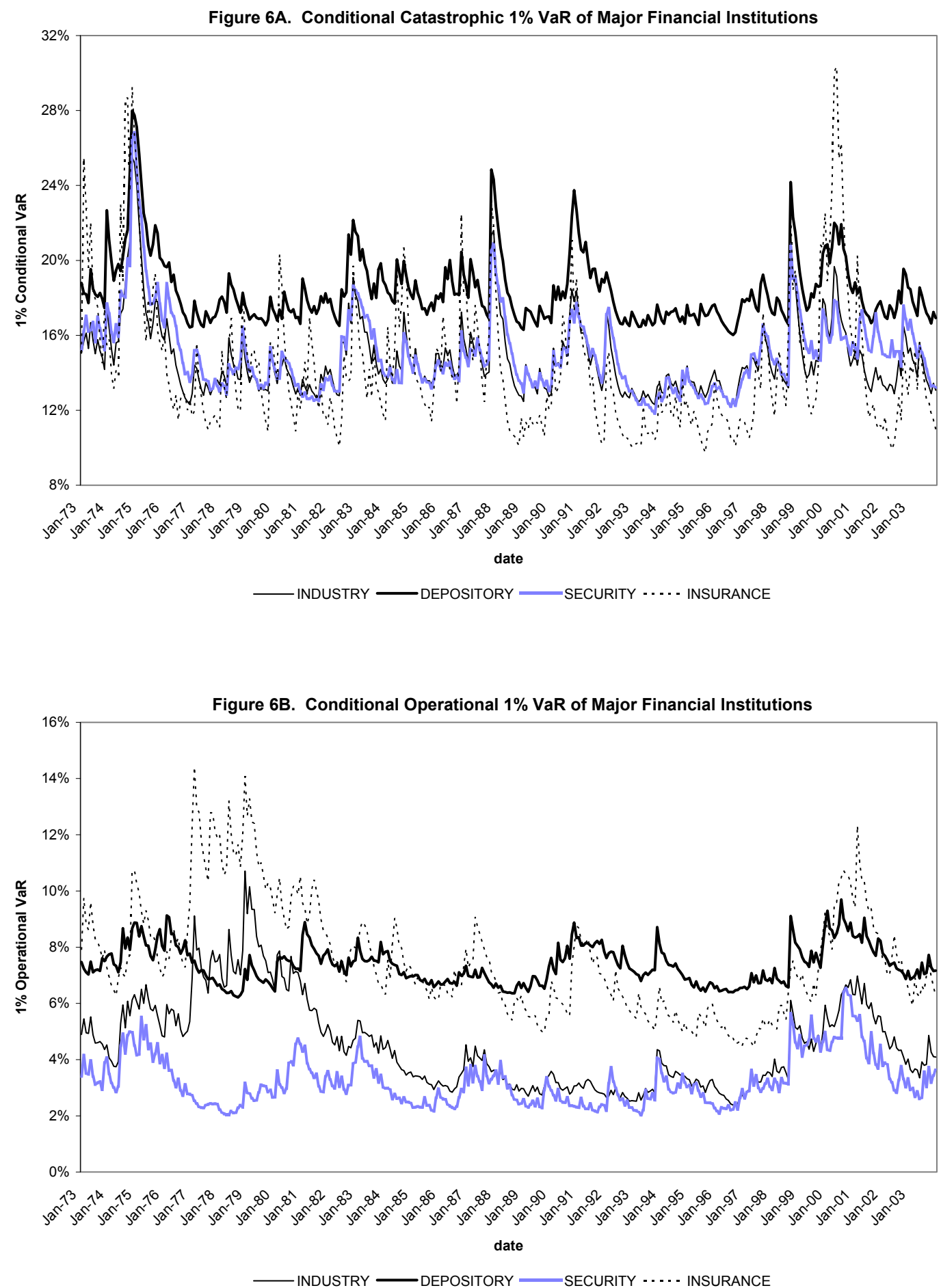
Figure 7. Comparison of Catastrophic and Operational 1\% VaR of GPD, SGED and SGT

Figures 7A and 7B compare the $1 \%$ catastrophic and operational VaR measures of GPD, SGED, and SGT. Since the VaR measures of SGT are smaller than those of the GPD and SGED, we assign a secondary axis to SGT to have a better picture of the time-series pattern of alternative VaR estimates.
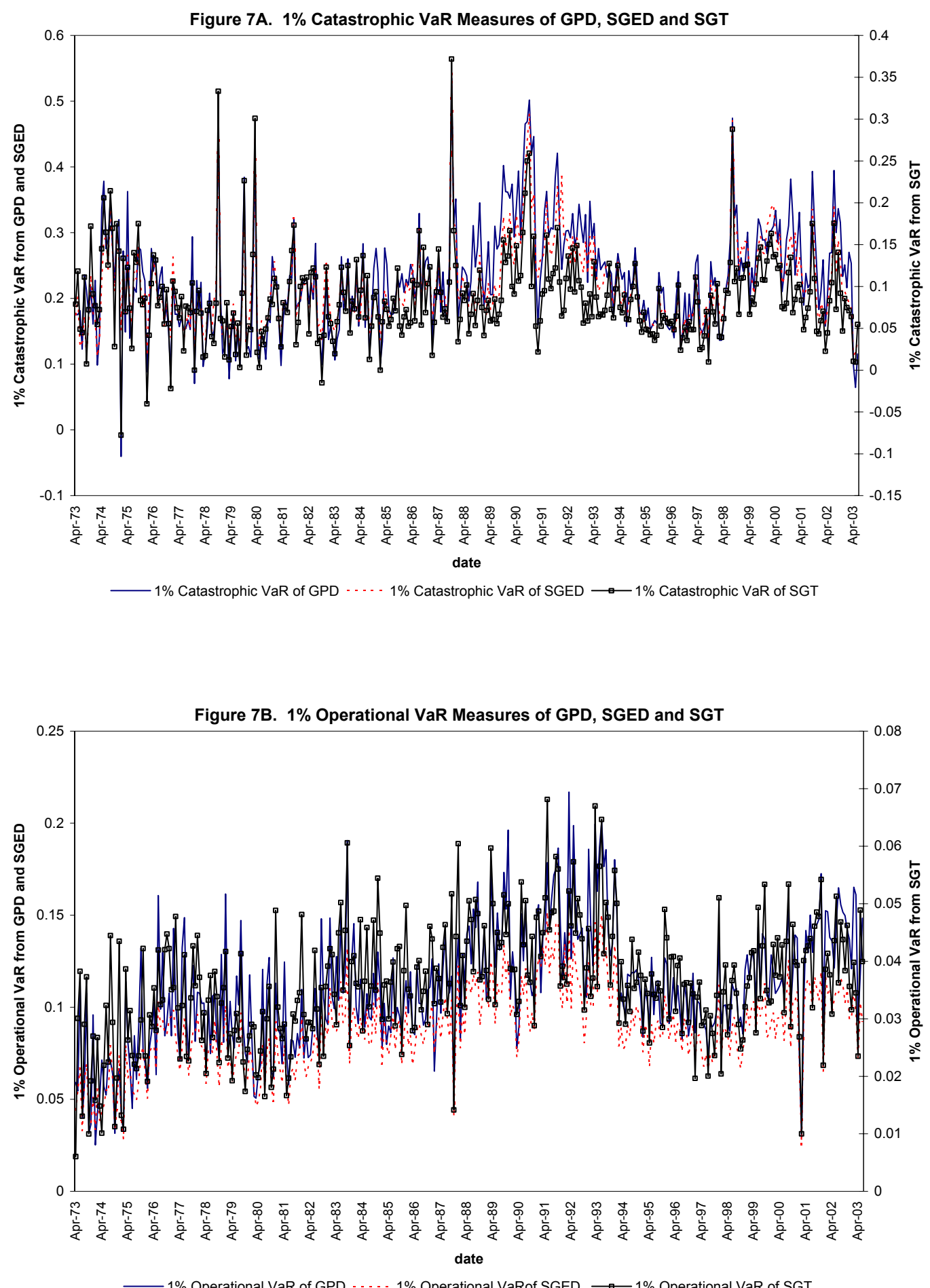